\title{
Thermal effects in landslide mobility
}

\author{
N. M. PINYOL*, M. ALVARADO†, E. E. ALONSO $\$$ and F. ZABALA§
}

\begin{abstract}
The paper describes a thermo-hydro-mechanical formulation to model thermally induced effects due to the irreversible work input generated during soil deformation. The model was implemented into a material point calculation procedure. The method is applied to the analysis of landslides. A simple slope stability is first analysed. Mechanical work essentially dissipates in shearing bands, which develop excess pore water pressures. The marked effect of soil permeability to control the slide motion after failure is described. Shear band thickness is also a relevant control variable. The problem posed by the non-realistic thickness of shear bands in numerical calculation is addressed by means of a numerical procedure that includes consideration of embedded shear bands where the strains are assumed to be localised. Balance equations describing local flow and thermal interactions between shear bands and the remaining material are formulated. The method is applied to model the instability and subsequent rapid motion of Vajont landslide. Calculated run-out and sliding velocity reproduce, in a satisfactory manner, field observations.
\end{abstract}

KEYWORDS: dynamics; landslides; numerical modelling; pore pressures; slopes; temperature effects

\section{INTRODUCTION}

One of the mechanisms invoked to explain the rapid acceleration of landslides is the heating of shearing bands induced by the mechanical energy dissipated during sliding. It leads to thermal-induced dilation of solid particles and water filling the pores in saturated soils, which, in turn, leads to increments of pore water pressure essentially dissipated as flow from the shear band towards the surrounding soil. As a result, effective frictional resistance forces reduce and the landslide accelerates.

The idea of explaining fast sliding due to heating generated by frictional work was first introduced by Habib (1967), who explained that the rapid motion of Vajont landslide was a consequence of the vapour pressure generated in the sliding surface. Later, Uriel Romero \& Molina (1977) combined a limit equilibrium model and the heat-induced water pressure to explain Vajont rapid motion. Voight \& Faust (1982) were the first to formulate the physics of the problem by combining the mass and heat balance equations inside the shear band and the dynamic equilibrium of the moving mass. Further contributions (Vardoulakis, 2000, 2002; Goren \& Aharonov, 2007, 2009; Veveakis et al., 2007; Cecinato et al., 2010; Goren et al., 2010; Pinyol \& Alonso, 2010a, 2010b; Cecinato \& Zervos, 2012; He et al., 2015; Alonso et al., 2016) followed the pioneering development by Voight \& Faust (1982) and introduced additional improvements.

Manuscript received 27 February 2017; revised manuscript accepted 19 July 2017. Published online ahead of print 4 September 2017. Discussion on this paper closes on 1 November 2018, for further details see p. ii.

* Centre Internacional de Metodes Numerics en Enginyeria, Department of Civil and Environmental Engineering, Universitat Politècnica de Catalunya, Barcelona, Spain (Orcid:0000-0002-18781365).

$\dagger$ Centre Internacional de Metodes Numerics en Enginyeria, Barcelona, Spain.

+ Department of Civil and Environmental Engineering, Universitat Politècnica de Catalunya, Barcelona, Spain (Orcid:0000-0003-24723951).

$\S$ Instituto de Investigaciones Antisísmicas (IDIA), Universidad Nacional de San Juan, San Juan, Argentina.
They concluded that the generated excess pore pressures were able to explain the acceleration of landslides.

The mentioned contributions share two simplifications: (a) the slope kinematics are solved in simple geometries defined by interacting solid blocks - often the motion is simply defined by a rigid body motion of a block sliding on a planar surface; and (b) dissipation of the mechanical work is concentrated in shear bands defining the contacts between rigid bodies.

These restrictions have been removed in the work reported here with the purpose of generalising the basic concepts and, also, with the ultimate aim of exploring the implications of thermally induced pore pressures on the vast majority of landslides, irrespective of their size, kinematic deformation mechanisms or assumptions concerning the dominant mode of energy dissipation. To do that, the dynamic behaviour of saturated soil under non-isothermal conditions has been formulated and integrated in a material point method (MPM) framework (Sulsky et al., 1995).

Various authors have approached the numerical analyses of the dynamic behaviour of porous media under different assumptions. For the case of saturated and isothermal conditions, Zienkiewicz \& Shiomi (1984) and Verruijt (2010) developed the governing equations based on the theoretical basis presented by Biot $(1941,1962)$ and Prevost (1980). Later, numerical approaches were formulated in finite elements (the finite-element method (FEM)) by Pastor et al. (1990), Huang et al. (2004), Jeremic et al. (2008) and Gajo \& Denzer (2011), among others. The general ' $u-w$ ' approach (a notation which refers to the displacement of the solid and the relative fluid displacement, respectively) can be reduced to the ' $u-p$ ' formulation (where $p$ is the pore water pressure) when material derivatives of the relative velocity of the fluid with respect to solid are neglected (Zienkiewicz et al., 1980, 1999; Zienkiewicz \& Shiomi, 1984; López-Querol et al., 2007). The $u-p$ formulation is able to capture the dynamic response for low-frequency phenomena.

Zienkiewicz et al. (1999), Schrefler \& Scotta (2001) and Uzuoka \& Borja (2012) extended the formulation to partially saturated soils. The non-isothermal dynamic analysis for non-saturated porous media (the $u-p-T$ approach) has been recently published by Cao et al. (2016). They included vapour pressure below the saturation water pressure 
(cavitation) and the evaporation of the pore liquid water due to thermal loads. Some application examples, solved by finite elements, involve small strains.

In this paper, the $u-p-T$ formulation has been developed for saturated porous media without including evaporation. In the cases and applications analysed here, the evaporation of the pore liquid pressure is not expected because of the range of temperatures developed. The governing equations have been solved and discretised numerically in the MPM with the aim of simulating the transition from static to dynamic conditions of landslides and the expected motion after failure. The $u-p$ formulation presented by Zhang et al. (2009) and Zabala \& Alonso (2011) is extended to nonisothermal conditions by including the energy balance equation and by applying the assumption that the mechanical plastic work generated dissipates in heat. The fundamental phenomena are highly coupled: $(a)$ plastic work and, therefore, thermal effects in the entire calculation domain are the result of sliding kinematics and the particular constitutive model; $(b)$ pore pressures are a consequence of the rate of temperature changes, but also their dissipation in real time because of flow effects; $(c)$ pore pressures and temperature modify the stress paths and the constitutive equations. These effects will be highlighted in the cases described in the paper.

The resulting MPM $u-p-T$ approach is capable of removing the limiting assumptions used so far to explore the thermal pressurisation effects on landslides. In fact, the kinematics of the motion should not be an assumption made 'a priori' but part of the solution. In general, heat sources are generated wherever plastic work develops.

The paper is organised as follows: first, the governing equations for saturated soils under non-isothermal conditions are presented. This formulation was integrated into a general MPM numerical code following an explicit Euler approach. The MPM GEOPART code (Zabala et al., 2004; Zabala \& Alonso, 2011) has been extended to include the energy balance. A reference case of an unstable saturated slope is then analysed to explore the effect of some relevant parameters. A key point regarding the effect of the shear band thickness on the motion of the landslides and the consequences of such dependence on the numerical modelling is later discussed. A methodology to overcome the mesh dependency under some assumptions is presented. The capabilities of the proposed methodology are evaluated by means of a reference case. Finally, the case of Vajont landslide (Hendron \& Patton, 1985) has been selected to apply the model because of the available information on the geometry, materials involved and velocity and displacement of the landslide motion.

\section{THERMO-HYDRO-MECHANICAL MPM FORMULATION FOR SATURATED SOILS \\ Basic governing equations for saturated conditions}

The equations are expressed in terms of the following primary unknown variables: acceleration of solid particles $\left(\boldsymbol{a}_{\mathrm{S}}\right)$, liquid pressure $\left(p_{\mathrm{L}}\right)$ and temperature $(\theta)$. Relative acceleration of the liquid with respect to the solid skeleton is assumed negligible $\left(\boldsymbol{a}_{\mathrm{L} / \mathrm{S}}=\boldsymbol{a}_{\mathrm{S}}-\boldsymbol{a}_{\mathrm{L}}=0 ; \boldsymbol{a}_{\mathrm{S}}=\boldsymbol{a}_{\mathrm{L}}\right)$. The formulation is then simplified to a $u-p$ formulation commonly used in finite-element implementation.

Momentum balance of the mixture. The equation of motion is formulated for both fluid and solid particles assuming the saturation of pores.

$$
\rho \boldsymbol{a}_{\mathrm{S}}=\boldsymbol{\nabla} \cdot \boldsymbol{\sigma}+\rho \boldsymbol{b}
$$

where $\boldsymbol{\sigma}$ is the Cauchy stress tensor, $\boldsymbol{b}$ is the body forces vector and $\rho$ is the density of the mixture defined as: $\rho=n \rho_{\mathrm{L}}+(1-n) \rho_{\mathrm{S}}$, where $n$ is the porosity and $\rho_{\mathrm{L}}$ and $\rho_{\mathrm{S}}$ are the fluid and solid density, respectively. $\nabla$ indicates the divergence vector operator.

Conservation of momentum of fluid. From the dynamic equilibrium equation for the fluid, the following generalised equation for Darcy flow rate, $\boldsymbol{q}_{\mathrm{L}}$, can be obtained

$$
\boldsymbol{q}_{\mathrm{L}}=-\frac{K}{\gamma_{\mathrm{L}}}\left(\boldsymbol{\nabla} p_{\mathrm{L}}-\rho_{\mathrm{L}} \boldsymbol{b}+\rho_{\mathrm{L}} \boldsymbol{a}_{\mathrm{L}}\right)
$$

where $\nabla p_{\mathrm{L}}$ is the gradient of pore water pressure, $\gamma_{\mathrm{L}}$ is the specific weight of liquid and $K$ is the permeability, also called hydraulic conductivity.

Mass balance of mixture. The mass balance equation of both solid particles and liquid can be expressed as follows

$$
n \frac{\mathrm{D} \rho_{\mathrm{L}}}{\mathrm{D} t}+\frac{\rho_{\mathrm{L}}}{\rho_{\mathrm{S}}}(1-n) \frac{\mathrm{D} \rho_{\mathrm{S}}}{\mathrm{D} t}+\rho_{\mathrm{L}} \boldsymbol{\nabla} \cdot \boldsymbol{v}_{\mathrm{S}}+\boldsymbol{\nabla} \cdot\left(\rho_{\mathrm{L}} \boldsymbol{q}_{\mathrm{L}}\right)=0
$$

where the material derivative is defined with respect to the solid as $\mathrm{D}(\cdot) / \mathrm{D} t=\partial(\cdot) / \partial t+\boldsymbol{v}_{\mathrm{S}} \boldsymbol{\nabla}(\cdot)$.

The Darcy's flow $q_{L}$ in equation (3) has been defined in equation (2).

Constitutive equations defining the variation of solid and liquid density are now introduced with the aim of expressing the governing equations in terms of the primary unknown variables. Exponential functions have been selected to define the density variations

$$
\begin{aligned}
& \rho_{\mathrm{S}}=\rho_{\mathrm{S}}^{0} \exp \left[-\beta_{\mathrm{S}}\left(\theta-\theta^{0}\right)\right] \\
& \rho_{\mathrm{L}}=\rho_{\mathrm{L}}^{0} \exp \left[\alpha_{\mathrm{L}}\left(p_{\mathrm{L}}-p_{\mathrm{L}}^{0}\right)-\beta_{\mathrm{L}}\left(\theta-\theta^{0}\right)\right]
\end{aligned}
$$

where $\rho_{\mathrm{S}}^{0}$ and $\rho_{\mathrm{L}}^{0}$ are the solid and liquid density at reference temperature $\theta^{0}$ and liquid pressure $p_{\mathrm{L}}^{0}$. The parameter $\alpha_{\mathrm{L}}$ defines the liquid phase compressibility and $\beta_{\mathrm{S}}, \beta_{\mathrm{L}}$ are the volumetric thermal expansion coefficients for solid and liquid phase, respectively. The compressibility of the solid particles against changes in stress is assumed to be negligible.

Taking into account equations (4) and (5), assuming constant constitutive parameters and assuming the distribution of the water density sufficiently smooth, the following mass balance equation is obtained

$$
n \alpha_{\mathrm{L}} \frac{\mathrm{D} p_{\mathrm{L}}}{\mathrm{D} t}-\beta \frac{\mathrm{D} \theta}{\mathrm{D} t}+\boldsymbol{\nabla} \cdot \boldsymbol{v}_{\mathrm{S}}+\boldsymbol{\nabla} \cdot \boldsymbol{q}_{\mathrm{L}}=0
$$

where a volumetric thermal expansion coefficient for the mixture $\beta=(1-n) \beta_{\mathrm{S}}+n \beta_{\mathrm{L}}$ is introduced.

Note that the spatial variation of the liquid density is neglected $\left(\nabla \rho_{\mathrm{L}} \approx 0\right)$.

Energy balance of mixture. The internal energy balance per unit of volume can be written as

$$
\begin{aligned}
& \frac{\mathrm{D}}{\mathrm{D} t}\left\{\left[n \rho_{\mathrm{L}} c_{\mathrm{L}}+(1-n) \rho_{\mathrm{S}} c_{\mathrm{S}}\right] \theta\right\}+\boldsymbol{\nabla} \cdot[-\Gamma \boldsymbol{\nabla} \theta] \\
& +\boldsymbol{\nabla} \cdot\left[\rho_{\mathrm{L}} c_{\mathrm{L}} \theta\left(\boldsymbol{q}_{\mathrm{L}}+n \boldsymbol{v}_{\mathrm{S}}\right)+(1-n) \rho_{\mathrm{S}} c_{\mathrm{S}} \theta \boldsymbol{v}_{\mathrm{S}}\right]=\dot{H}
\end{aligned}
$$

which states that the external supply of heat rate, $\dot{H}$, should be equal to the sum of the following terms: $(a)$ internal energy in solid and liquid phase, which depends on their specific heats, $c_{\mathrm{S}}$ and $c_{\mathrm{L}}$, respectively; $(b)$ the heat flow conduction driven by temperature gradients (Fourier's law), 
which depends on the thermal conductivity coefficient, $\Gamma$; and $(c)$ the convective heat transport due to liquid and solid flows.

Assuming that the specific heat of the phases remains constant, equation (7) can be simplified to

$$
(\rho c)_{\mathrm{m}} \frac{\mathrm{D} \theta}{\mathrm{D} t}+\boldsymbol{\nabla} \cdot \boldsymbol{q}_{\mathrm{h}}+\rho_{\mathrm{L}} c_{\mathrm{L}} \theta \boldsymbol{\nabla} \cdot \boldsymbol{q}_{\mathrm{L}}+(\rho c)_{\mathrm{m}} \theta \boldsymbol{\nabla} \cdot \boldsymbol{v}_{\mathrm{S}}=\dot{H}
$$

where the specific heat of the mixture has been defined as $(\rho c)_{\mathrm{m}}=n \rho_{\mathrm{L}} c_{\mathrm{L}}+(1-n) \rho_{\mathrm{S}} c_{\mathrm{S}}$ and

$$
\boldsymbol{q}_{\mathrm{h}}=-\Gamma \nabla \theta
$$

is the heat flow conduction.

First law of thermodynamics. It is assumed that the plastic work rate

$$
\dot{H}=\sigma^{\prime}: \dot{\varepsilon}^{\mathrm{p}}
$$

dissipates in heat. In equation (10)

$$
\boldsymbol{\sigma}^{\prime}=\boldsymbol{\sigma}-p_{\mathrm{L}} \mathbf{m}
$$

is the effective stress tensor, $\mathbf{m}$ is defined by means of $m_{i j}=\delta_{i j}$ and $\delta_{i j}$ is the Kronecker delta. $\dot{\varepsilon}^{\mathrm{p}}$ is the plastic strain rate.

Constitutive equations of the porous media. A constitutive law

$$
\mathrm{d} \boldsymbol{\sigma}^{\prime}=\mathbf{D} \cdot \mathrm{d} \boldsymbol{\varepsilon}
$$

where $\mathbf{D}$ is the tangent matrix and defines the relationship between effective stress and strains.

In this paper, the soil behaviour is characterised by means of an elastoplastic Mohr-Coulomb model. Alternatively, more complex constitutive models could be defined. However, since the main purpose of the paper is to model the response of landslides including thermal effects, this is a proper option to simulate the shearing behaviour of soils in first-time failures (Zabala \& Alonso, 2011; Yerro et al., $2016 \mathrm{a}, 2016 \mathrm{~b})$. The yield surface is defined in terms of effective cohesion, $c^{\prime}$, and effective friction angle, $\phi^{\prime}$, whose values decrease exponentially with the accumulated deviatoric plastic strain invariant $\varepsilon_{\mathrm{d}}^{\mathrm{p}}=\sqrt{2 / 3\left(e_{i j}^{\mathrm{p}} e_{i j}^{\mathrm{p}}\right)}$, where $e_{i j}^{\mathrm{p}}$ is the deviatoric part of the plastic strain tensor as follows

$$
c^{\prime}=c_{\text {res }}^{\prime}+\left(c_{\text {peak }}^{\prime}-c_{\text {res }}^{\prime}\right) \mathrm{e}^{-\eta \varepsilon_{\mathrm{d}}^{\mathrm{p}}}
$$

$$
\phi^{\prime}=\phi_{\text {res }}^{\prime}+\left(\phi_{\text {peak }}^{\prime}-\phi_{\text {res }}^{\prime}\right) \mathrm{e}^{-\eta \varepsilon_{\mathrm{d}}^{\mathrm{p}}}
$$

Peak and residual values of cohesion and friction angle indicated by the subindex 'res' and 'peak', respectively, are model parameters. The rate of the strength decrease is controlled by the softening shape factor $\eta$.

\section{ANALYSIS OF A REFERENCE CASE}

The performance of the thermo-hydro-mechanical formulation was first tested by means of a two-dimensional (2D) numerical stability analysis. Consider in Fig. 1 the geometry of a homogeneous saturated slope. For this case, the soil is described by a perfectly plastic Mohr-Coulomb model defined by an effective friction angle equal to $28^{\circ}$ and an effective cohesion equal to $2 \cdot 0 \mathrm{kPa}$. The rest of the parameters are indicated in Table 1. A square support mesh $(12.5 \times 12.5 \mathrm{~cm})$ defines the computational domain (also plotted in Fig. 1). Four particles per element are initially located at each fill element representing the soil of the slope. The slope failure is triggered by the simple procedure of reducing the cohesion from $2 \mathrm{kPa}$ to $1 \mathrm{kPa}$.

An isothermal case (no source term in the energy balance equation) defines the reference case. Fig. 2(a) shows the accumulated displacement computed at the end of the motion (once the slope recovers a new stable geometry) $5 \mathrm{~s}$ after failure triggering. The distance between the initial and the final position of the slope toe is equal to $1.7 \mathrm{~m}$.

According to the previous works published by Goren \& Aharonov (2009) and Pinyol \& Alonso (2010a, 2010b), heating effects on the landslide motion are highly dependent on the pore water pressure dissipation, mainly controlled by the value of the saturated permeability. In those papers, the problem was analysed for simple geometries and the thermo-hydro-mechanical problem was solved at the scale of the shear band coupled with the momentum balance equations defining the whole motion of the unstable mass. The conclusion derived from the sensitivity analyses performed was clear: given a slope, a range of permeability values can be defined which separate rapidly accelerating landslides from non-accelerated landslides. For relatively low values of permeability, excess pore water pressure generated during the motion cannot dissipate and its accumulation induces the acceleration of the landslide, which feeds back the motion. On the contrary, higher values of permeability allow the dissipation of the excess pore pressures and the motion slows down. In this case, when compound landslides are analysed (Pinyol \& Alonso, 2010b), changes in the slope geometry during the motion make the slope more stable and, after a certain time, the acceleration reduces and the slide

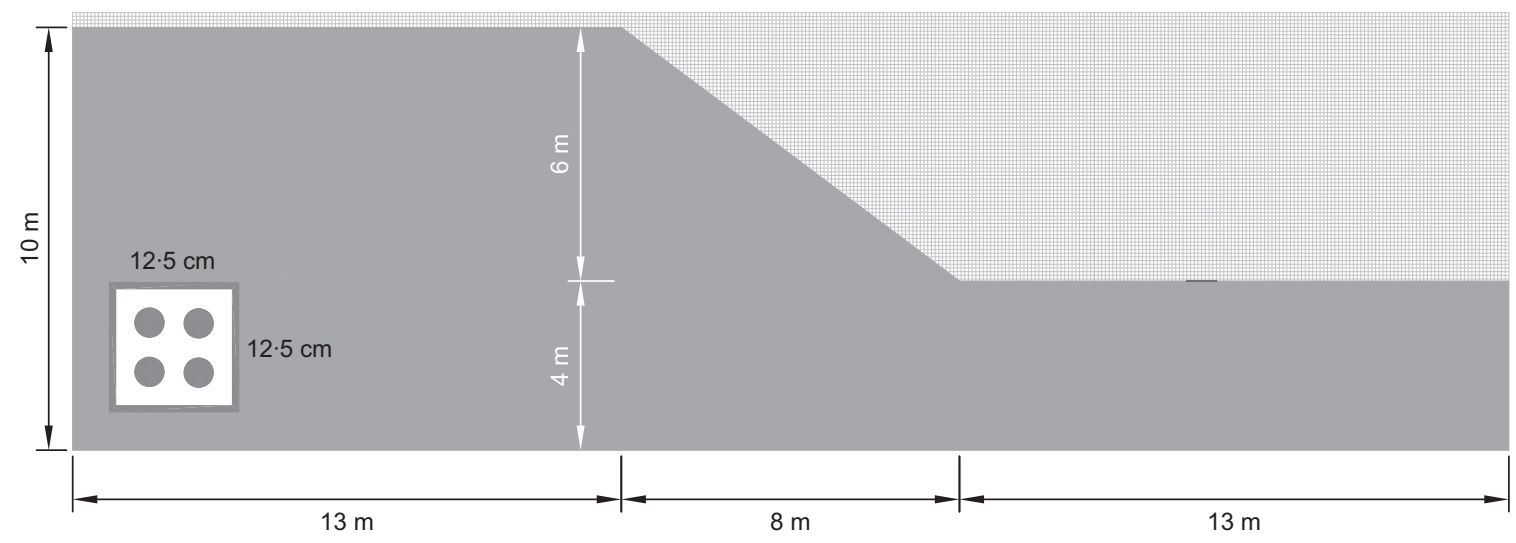

Fig. 1. Slope geometry and discretisation of the reference case 
Table 1. Model parameters

\begin{tabular}{|c|c|c|c|}
\hline Parameters & Symbol & Value & Units \\
\hline \multicolumn{4}{|l|}{ Water } \\
\hline Density & $\rho_{\mathrm{L}}$ & 1000 & $\mathrm{~kg} / \mathrm{m}^{3}$ \\
\hline Bulk modulus & $\alpha_{\mathrm{L}}$ & 2200 & MPa \\
\hline $\begin{array}{l}\text { Thermal dilation } \\
\text { coefficient }\end{array}$ & $\beta_{\mathrm{L}}$ & $0 \cdot 00034$ & $1 /{ }^{\circ} \mathrm{C}$ \\
\hline Specific heat & $c_{\mathrm{L}}$ & $\begin{array}{l}4186 \\
1\end{array}$ & $\begin{array}{l}\mathrm{N} \mathrm{m} /\left(\mathrm{kg}^{\circ} \mathrm{C}\right) \\
\mathrm{cal} /\left(\mathrm{kg}^{\circ} \mathrm{C}\right)\end{array}$ \\
\hline \multicolumn{4}{|l|}{ Solid particles } \\
\hline Density & $\rho_{\mathrm{S}}$ & 2700 & $\mathrm{~kg} / \mathrm{m}^{3}$ \\
\hline $\begin{array}{l}\text { Thermal dilation } \\
\text { coefficient }\end{array}$ & $\beta_{\mathrm{S}}$ & $0 \cdot 00003$ & $1 /{ }^{\circ} \mathrm{C}$ \\
\hline Specific heat & $c_{\mathrm{S}}$ & $\begin{array}{l}837 \\
0 \cdot 2\end{array}$ & $\begin{array}{l}\mathrm{N} \mathrm{m} /\left(\mathrm{kg}^{\circ} \mathrm{C}\right) \\
\mathrm{cal} /\left(\mathrm{kg}{ }^{\circ} \mathrm{C}\right)\end{array}$ \\
\hline \multicolumn{4}{|l|}{ Clay Soil } \\
\hline Porosity & $n$ & $0 \cdot 4$ & - \\
\hline Permeability & $K$ & $1.00 \times 10^{-11}$ & $\mathrm{~m} / \mathrm{s}$ \\
\hline Young's modulus & $E$ & 20000 & $\mathrm{kPa}$ \\
\hline Poisson ratio & $v$ & $0 \cdot 33$ & - \\
\hline
\end{tabular}

run-out is shorter, if compared with the case of more impervious shearing bands.

Consider now the effect of permeability when thermal effects are activated in the model slope (Figs 2(b) and 2(c)). The slope response for the more pervious case $\left(K=10^{-5} \mathrm{~m} / \mathrm{s}\right)$ does not change if compared with the isothermal case. However, the thermal effects lead to an increased slide run-out in the more impervious case $\left(K=10^{-11} \mathrm{~m} / \mathrm{s}\right)$.

The slide motion depends not only on the soil permeability, but also on the shear band thickness because this dimension is involved in the accumulation of plastic work per unit of volume of soil inside the band as well as in the pore pressure and heat dissipation towards the surrounding soil. Shear band thickness in the reference case depends on the size of computational mesh. This introduces a meshdependent problem which will be addressed below.

\section{Effect of the shear band thickness}

Consider the effect of the shear band thickness illustrated by a simple example. Fig. 3 shows two reference volumes subjected to shear deformation defined by a rate of

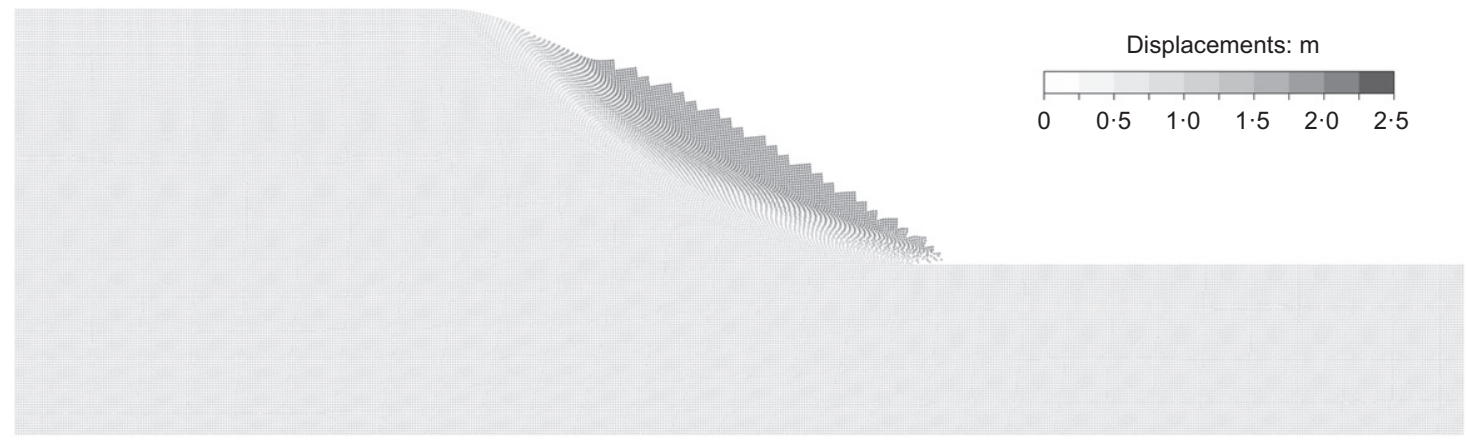

(a)

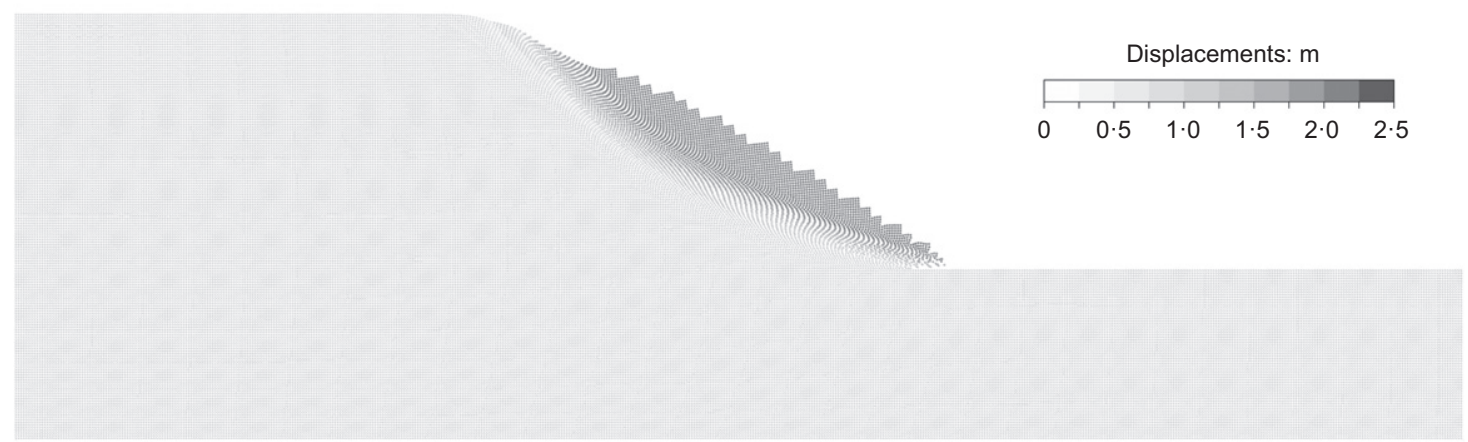

(b)

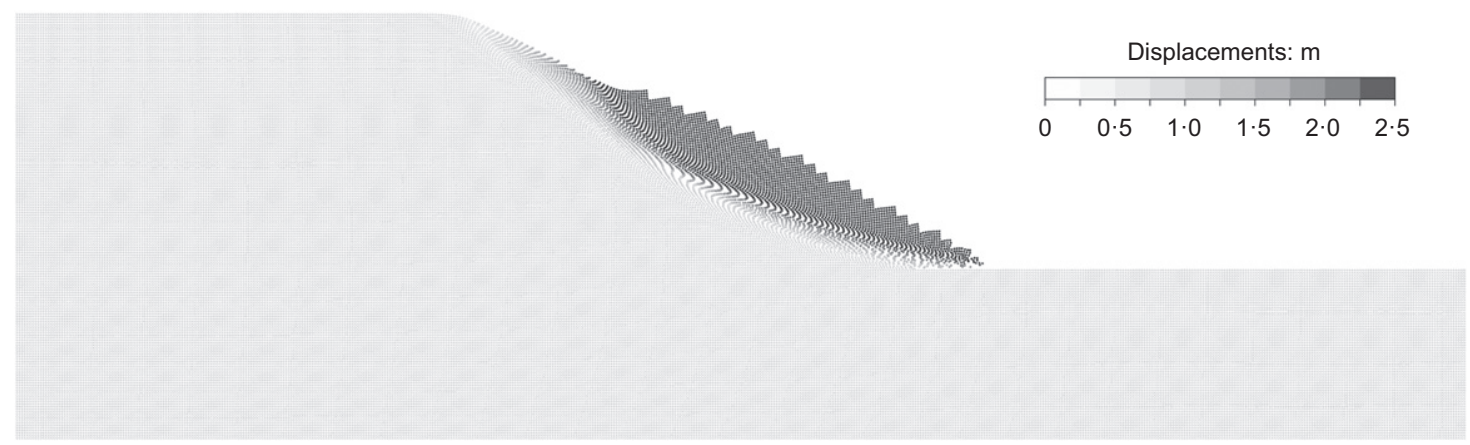

(c)

Fig. 2. Accumulated displacements at the end of the motion for the reference case: (a) heating effects not included; (b) heating effects included and $K=10^{-5} \mathrm{~m} / \mathrm{s}$; (c) heating effects included and $K=10^{-11} \mathrm{~m} / \mathrm{s}$ 

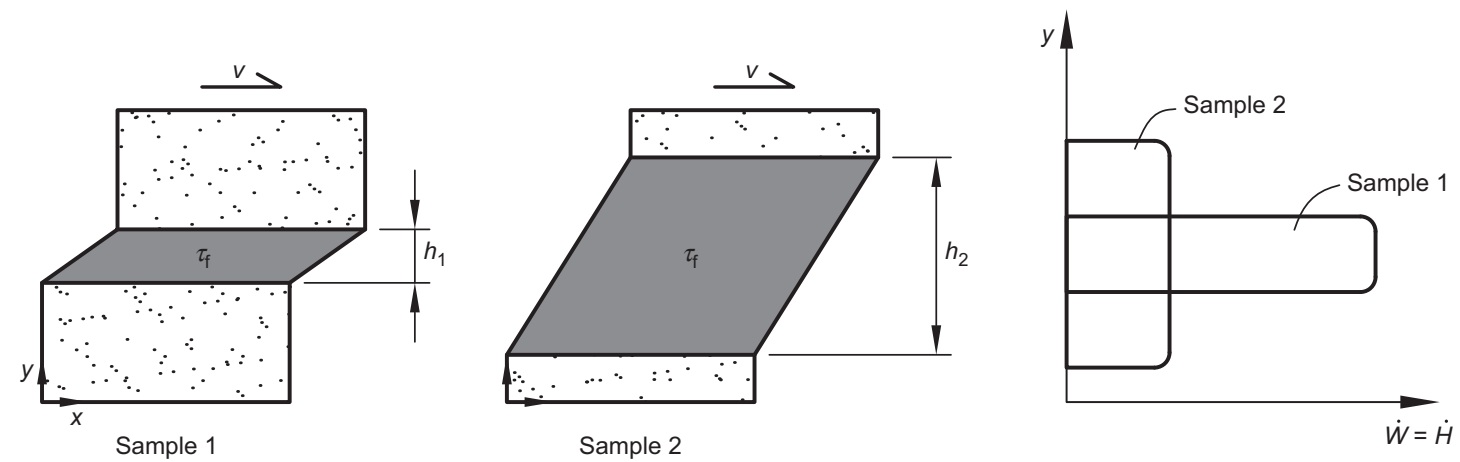

Fig. 3. Schematic representation of two shear bands exhibiting different shear band thicknesses

displacement $\dot{\delta}$. It is assumed that the shear band of each sample has a different thickness. For simplicity, a planar deformation is assumed. Accepting a linear distribution of the shear strains inside the sheared zone and assuming that the soils are at failure, the rate of the generated mechanical work per unit volume can be calculated as

$$
\begin{aligned}
& \dot{W}_{1}=\tau_{\mathrm{f}} \dot{\gamma}_{1}=\tau_{\mathrm{f}} \frac{\dot{\delta}}{h_{1}} \\
& \dot{W}_{2}=\tau_{\mathrm{f}} \dot{\gamma}_{2}=\tau_{\mathrm{f}} \frac{\dot{\delta}}{h_{2}}
\end{aligned}
$$

where $\tau_{\mathrm{f}}$ is the shear strength, $\dot{\gamma}$ is the shear strain rate and 1 and 2 refer to the reference volumes represented in Fig. 3. According to this, the dissipated work per unit of volume depends on the thickness of the shear band; however, the total work on the band volume will be equal for both cases (see the far-right-hand image in Fig. 3)

$$
\dot{W}_{1} h_{1} l=\dot{W}_{2} h_{2} l=\tau_{\mathrm{f}} \dot{\delta} l
$$

Since temperature increments are computed from the heat generated per unit of volume (equation (10)), higher increments of temperature and pore water pressure are expected in the case of the thinnest shear band.

The effect of the shear band thickness can be derived for the case of a simple block sliding on a horizontal surface at an imposed constant velocity $(v)$ subjected to a normal stress $\left(\sigma_{\mathrm{n}}\right)$ (Fig. 4). With the aim of obtaining an analytical solution, heat and pore water pressure dissipation will be neglected. Under these assumptions, the system of equations given in the earlier section entitled 'Thermo-hydro-mechanical MPM formulation for saturated soils' reduces to the following differential equation

$$
\frac{\mathrm{d} p_{\mathrm{L}}}{\mathrm{d} t}=\frac{\beta \tan \phi^{\prime} v}{\left(m_{\mathrm{v}}+n \alpha_{\mathrm{L}}\right)(\rho c)_{\mathrm{m}} 2 e}\left(\sigma_{\mathrm{n}}-p_{\mathrm{L}}\right)
$$

where the unknown variable is the excess pore water pressure $\left(p_{\mathrm{L}}\right)$ in time, $2 e$ is the thickness of the shear band and $m_{\mathrm{v}}$ is

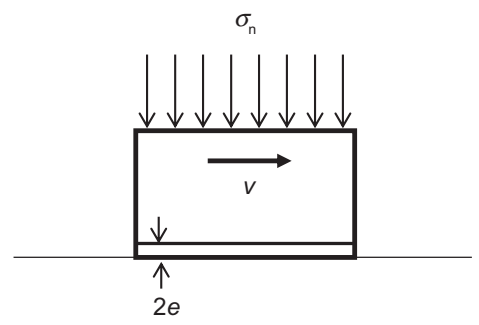

Fig. 4. Loaded block sliding at constant velocity the oedometric compressibility coefficient. Equation (18) has the following analytical solution

$$
p_{\mathrm{L}}=\sigma_{\mathrm{n}}\left\{1-\exp \left[-\frac{\beta \tan \phi^{\prime} v}{\left(m_{\mathrm{v}}+n \alpha_{\mathrm{L}}\right)(\rho c)_{\mathrm{m}} 2 e} t\right]\right\}
$$

which is represented in Fig. 5 for the case of an imposed velocity of $0.1 \mathrm{~m} / \mathrm{s}$, a normal stress $\sigma_{\mathrm{n}}=1 \mathrm{MPa}$, an oedometric compressibility coefficient equal to $m_{\mathrm{v}}=1.5 \times 10^{-3} \mathrm{MPa}^{-1}$ and different values of shear band thickness. The rest of the parameters are selected according to Table 1 . The results show a large effect of the shear band thickness: the larger the shear band thickness, the lower the excess pore water pressures generated.

However, the thickness of the shear band also has an influence on the liquid pressure and temperature dissipation, which has been neglected in the previous analytical solution. Following the simple example illustrated in Fig. 3, the heat-induced increments of temperature and liquid pressure will be distributed homogeneously inside the shear band. For a given soil permeability, the dissipation will be faster in the case of the thinner shear band because of the higher water pressure gradients.

The thickness of shear band depends on the grain size distribution of soils (Vardoulakis, 1980; Scarpelli \& Wood, 1982; Mühlhaus \& Vardoulakis, 1987; Alshibli \& Hasan, 2008). A sensitivity analysis of the effect of the shear band thickness on landslide behaviour including thermal effects was given by Pinyol \& Alonso (2010a), Pinyol \& Alonso (2010b) and Alonso et al. (2016). They solved the thermo-hydro-mechanical coupled phenomena at the scale of the shear band as a one-dimensional (1D) problem and solved it by finite differences. The geometry of the slide and the position of the sliding surface were predefined in these

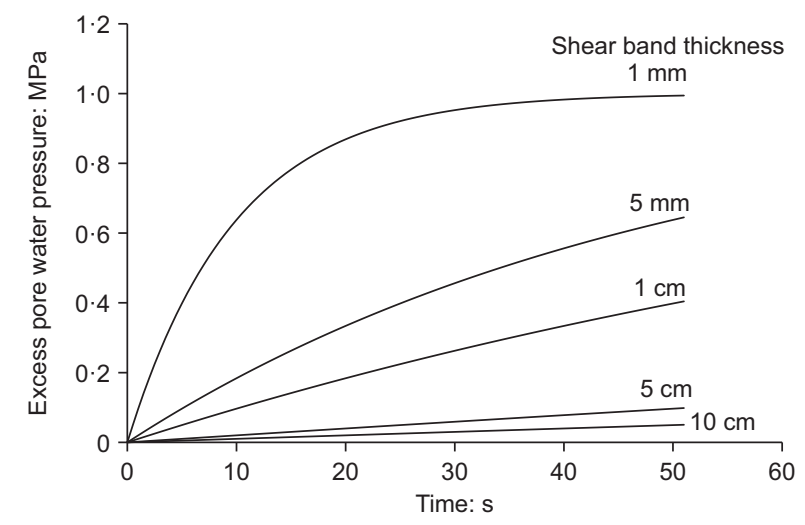

Fig. 5. Analytical results for the excess pore water pressure for different values of shear band thickness in the case of a planar motion on a horizontal surface at constant imposed velocity 
contributions and they do not depend on the numerical discretisation. The thickness of the shear band was also defined as input data and it does not depend on the element size of the finite-difference discretisation.

Alonso et al. (2016) also solved the case of a zero-thickness shear band. In this case, the shear band was assumed to be a contact plane and the heat generated was included as a boundary condition. A heat flow per unit of surface of the sliding plane, calculated as the product of the shear strength and the landslide velocity, was imposed. Heat inflow induces the increments of temperature that lead to increments in pore water pressure. Based on the analyses performed, they concluded that, for realistic shear band thicknesses (in the range of few millimetres including also the zero-thickness case), the results in terms of pore liquid pressure, temperature and landslide velocity are not significantly different among them. This is an interesting conclusion, and suggests that it is not necessary to specify the shear band thickness, which is always difficult to quantify.

However, when the shear band thickness increases, the results are significantly affected. The case is analysed here following the 1D finite-difference analysis presented in Alonso et al. (2016) for a planar landslide described in Fig. 6(a), which corresponds to a situation of strict equilibrium. Consider a case of a low value of permeability $\left(K=10^{-11} \mathrm{~m} / \mathrm{s}\right)$. The rest of the parameters are indicated in Table 1. The landslide is triggered by increasing the water level by $10 \mathrm{~cm}$. The results in terms of landslide velocity during the first $50 \mathrm{~m}$ of travelling are plotted in Fig. 6(b) for different values of shear band thickness, ranging from $1 \mathrm{~mm}$ to $1 \mathrm{~m}$. The pore water pressure dissipation during the motion is negligible in all cases. The isothermal case is also included in the plot. The results show that the effect of the shear band thickness becomes relevant for values higher than $1 \mathrm{~cm}$.

In numerical approaches such as FEM, finite-difference method and MPM, the size of the shear band developed

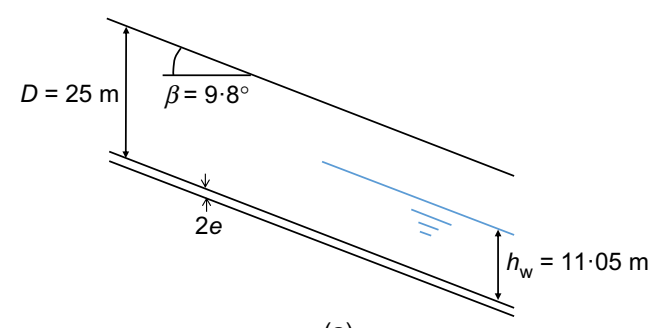

(a)

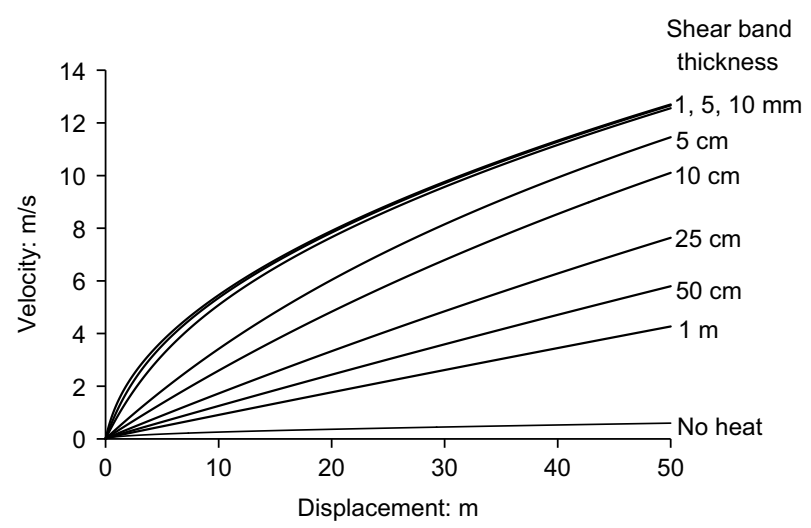

(b)

Fig. 6. (a) Scheme of a planar slide. (b) Effect of the shear band thickness on the velocity for $K=10^{-11} \mathrm{~m} / \mathrm{s}$. 1D finite-difference analysis when shear strains localise depends on the element size and on the inclination of the band with respect to the mesh lines. In practice, strains tend to localise into a single or a few elements. Therefore, in view of the previous results (Fig. 6(b)), the size of the elements of the computational mesh in an MPM numerical model should be similar to the thickness of the actual shear band (i.e. few millimetres or perhaps centimetres) in order to obtain realistic results. Otherwise, the computed heat generated in the slip zone per unit of volume will be lower than the heat actually generated. However, in real landslide modelling, the size of landslides requires element sizes in the order of decimetres or metres if the computational cost is to be kept within limited and tractable limits, especially in cases of coupled thermohydro-mechanical analysis.

It follows that a direct application of equation (10) to calculate the energy dissipated in a shear band will result in work rates per unit volume significantly smaller that the rates dissipated in real sliding surfaces. The consequence is an underestimation of excess pore pressures generated in shear bands. This effect can be readily observed in a mesh size sensitivity analysis of the reference case discussed in the previous section for a low value of permeability $\left(K=10^{-11} \mathrm{~m} / \mathrm{s}\right)$. The case has been run again using two additional coarser discretisations described by square meshes of $0.5 \times 0.5 \mathrm{~m}$ and $0.25 \times 0.25 \mathrm{~m}$. The calculated displacement and excess pore water pressure at the end of the motion are plotted in Figs 7 and 8, respectively. Both depend markedly on the mesh size. A numerical alternative to overcome such dependency is described in the next section.

\section{EMBEDDED SHEAR BANDS}

A numerical procedure has been developed in order to consider the real shear band thickness when performing numerical modelling of thermo-hydro-mechanical phenomena in landslides. It should be noted that the proposed procedure does not provide a methodology to solve the mesh dependence effect in strain localisation problems simulated by continuous numerical models such as FEM and MPM (caused or not by strength softening). The proposed procedure provides a solution to account properly for the magnitude of the heat and excess pore water pressure generated because of the generated frictional work and their dissipation, which depends on the shear band thickness.

The idea was to include a set of embedded shear bands into the material domain whenever the plastic deviatoric strain exceeds a reference value. Fig. 9 illustrates the explanation. A reference volume corresponding to the volume initially assigned to each material point is characterised by a reference length, $L_{\text {ref. }}$ The strain computed at each material point will be assumed to be localised in an embedded shear band whose thickness will be given as an input parameter, $L_{\mathrm{B}}$, which will depend on the soil type. Heat due to friction work dissipation and the induced liquid pressure will be assumed to be generated into the embedded elements. Different variables for temperature and liquid pressure in the embedded shear bands and the rest of the soil are defined: $\theta^{\mathrm{B}}, \theta^{\mathrm{M}}, p_{\mathrm{L}}^{\mathrm{B}}, p_{\mathrm{L}}^{\mathrm{M}}$, respectively. Dissipation processes of heat and liquid flow between the embedded shear bands and the rest of the material domain, called the matrix, will be formulated at local level. Energy and mass balance equations are now formulated at matrix and embedded shear band level as follows

$$
\begin{aligned}
& \frac{\mathrm{D}}{\mathrm{D} t}\left[(\rho c)_{\mathrm{m}} \theta^{\mathrm{M}}\right]+\boldsymbol{\nabla} \cdot\left[-\Gamma \boldsymbol{\nabla} \theta^{\mathrm{M}}\right] \\
& +\boldsymbol{\nabla} \cdot\left[\rho_{\mathrm{L}} c_{\mathrm{L}} \boldsymbol{q} \theta^{\mathrm{M}}+(\rho c)_{\mathrm{m}} \boldsymbol{v}_{\mathrm{S}} \theta^{\mathrm{M}}\right]=f_{\theta}^{\mathrm{B}-\mathrm{M}}
\end{aligned}
$$




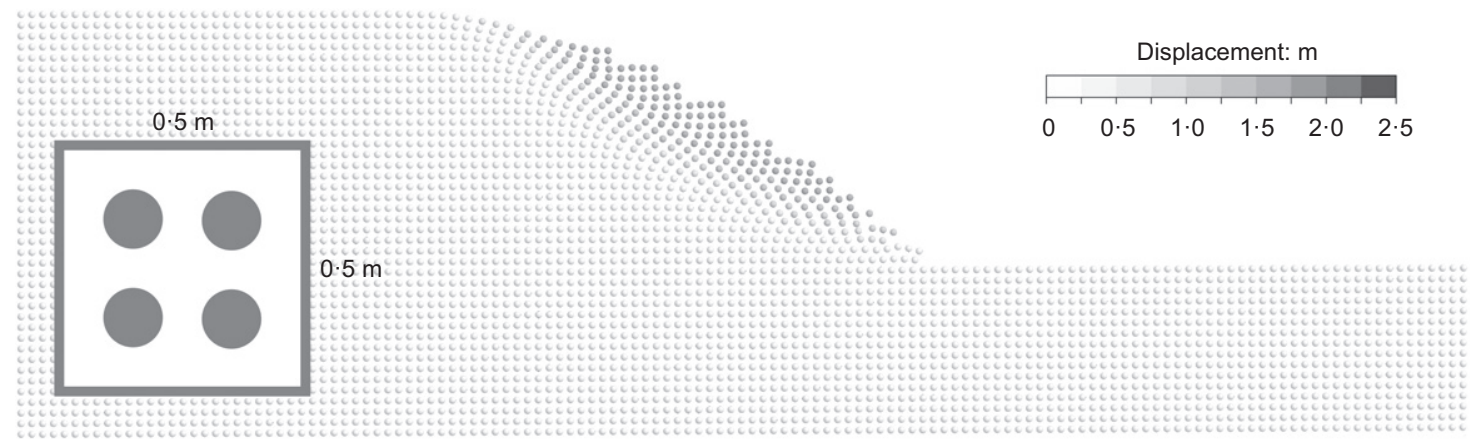

(a)

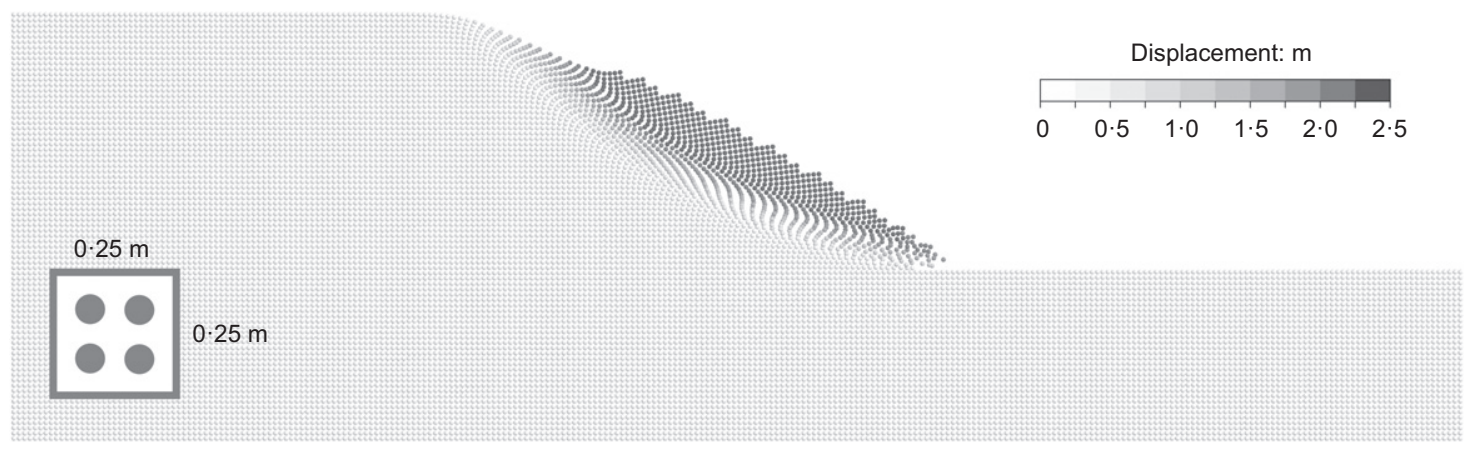

(b)

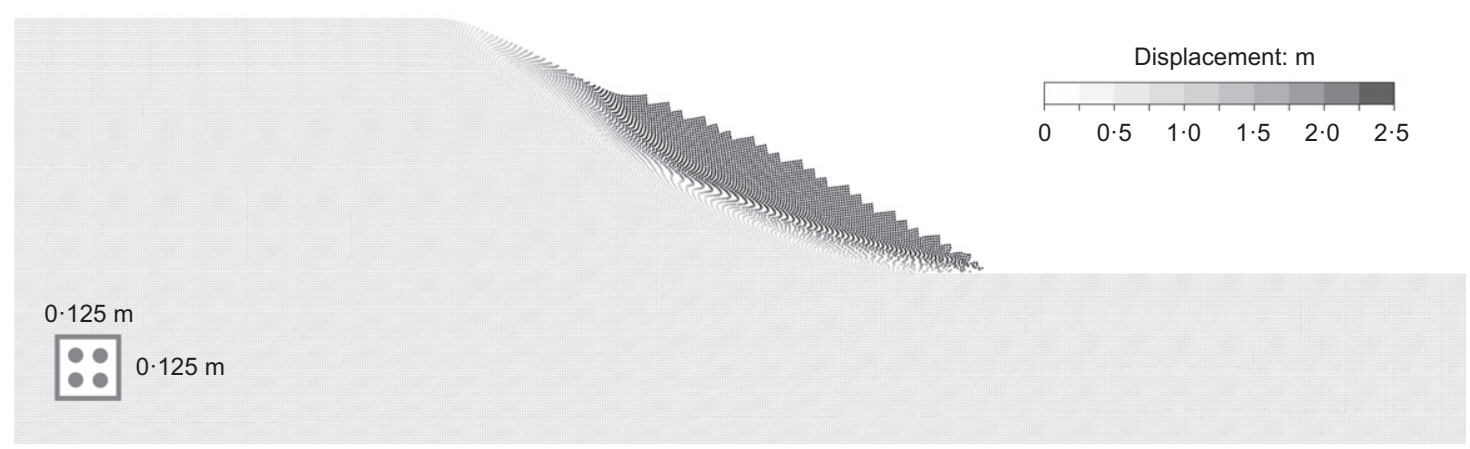

(c)

Fig. 7. Maximum displacement calculated for the reference case for a permeability value of $K=10^{-11} \mathrm{~m} / \mathrm{s}$ and for different sizes of mesh elements (indicated in the figure)

$$
\begin{aligned}
& \frac{\mathrm{D}}{\mathrm{D} t}\left[(\rho c)_{\mathrm{m}} \theta^{\mathrm{B}}\right]=-f_{\theta}^{\mathrm{B}-\mathrm{M}}+\dot{H}^{\mathrm{B}} \\
& \frac{\mathrm{D}}{\mathrm{D} t}\left[\beta \theta^{\mathrm{M}}\right]+n \alpha_{\mathrm{L}} \frac{\mathrm{D} p_{\mathrm{L}}^{\mathrm{M}}}{\mathrm{D} t}+\nabla \cdot \boldsymbol{v}_{\mathrm{S}}+\nabla \cdot \boldsymbol{q}_{\mathrm{L}}=\frac{1}{\rho_{\mathrm{L}}} f_{\mathrm{L}}^{\mathrm{B}-\mathrm{M}} \\
& \frac{\mathrm{D}}{\mathrm{D} t}\left[\beta \theta^{\mathrm{B}}\right]+n \alpha_{\mathrm{L}} \frac{\mathrm{D} p_{\mathrm{L}}^{\mathrm{B}}}{\mathrm{D} t}=-\frac{1}{\rho_{\mathrm{L}}} f_{\mathrm{L}}^{\mathrm{B}-\mathrm{M}}
\end{aligned}
$$

Local source terms of heat and liquid flow rate per unit of volume and time are included in the balance equations to take into account the dissipation of heat and liquid pressure between matrix and embedded elements. Flow rates are defined proportional to the difference between band and matrix temperature and liquid pressure

$$
\begin{aligned}
& f_{\mathrm{L}}^{\mathrm{B}-\mathrm{M}}=\psi_{\mathrm{L}}\left(p_{\mathrm{L}}^{\mathrm{B}}-p_{\mathrm{L}}^{\mathrm{M}}\right) \\
& f_{\theta}^{\mathrm{B}-\mathrm{M}}=\psi_{\theta}\left(\theta^{\mathrm{B}}-\theta^{\mathrm{M}}\right)
\end{aligned}
$$

$\psi_{\mathrm{L}}$ and $\psi_{\theta}$ are defined as liquid and energy transfer coefficients, respectively.

Equation (21a) for the local liquid source term, $f_{\mathrm{L}}^{\mathrm{B}-\mathrm{M}}$ (mass per unit volume per unit time) is approximated in terms of a difference in pressures to facilitate the calculation at the local level. From a physical perspective it should be related to the gradient of pressures through some permeability coefficient. This consideration suggests that the transfer coefficient, $\psi_{\mathrm{L}}$, has the following structure

$$
\psi_{\mathrm{L}}=\frac{\rho_{\mathrm{L}} k}{\mu_{\mathrm{L}} A_{\text {ref }}}
$$

expressed in terms of liquid density, $\rho_{\mathrm{L}}$, liquid viscosity, $\mu_{\mathrm{L}}$, intrinsic permeability, $k$, Fourier's coefficient, $\Gamma$, and a reference area, $A_{\text {ref. }}$ This area is directly related to the expected distance of fluid transfer from the shear band, included in a material point, and the surrounding clay matrix associated with the material point under consideration. Therefore, $A_{\text {ref }}$ was made equal to the element area contributing to the material point (one quarter of the element area if four material points per element are adopted). A similar argument, in the case of local heat 


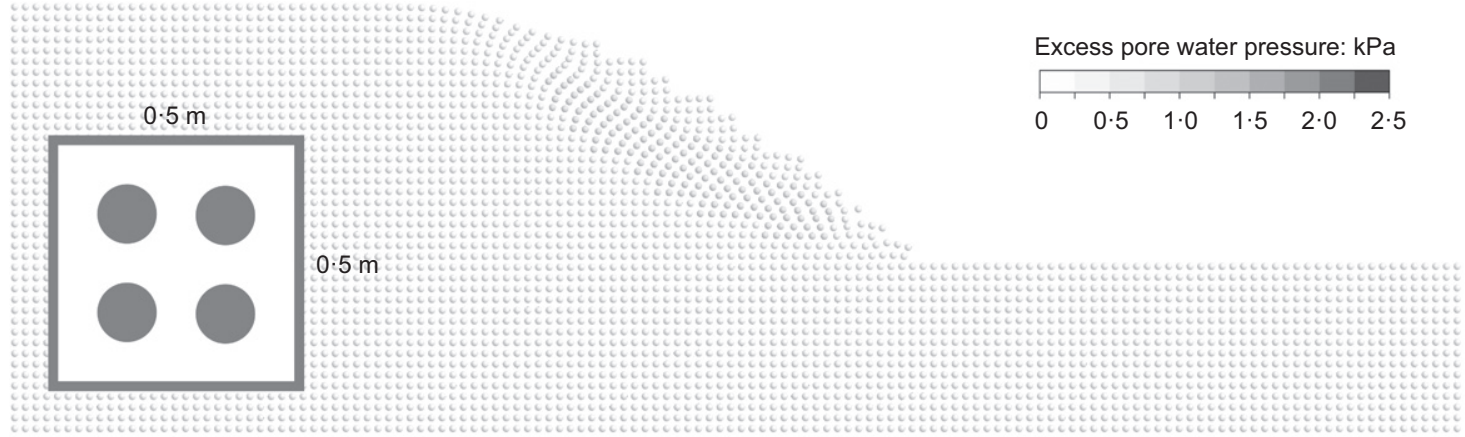

(a)

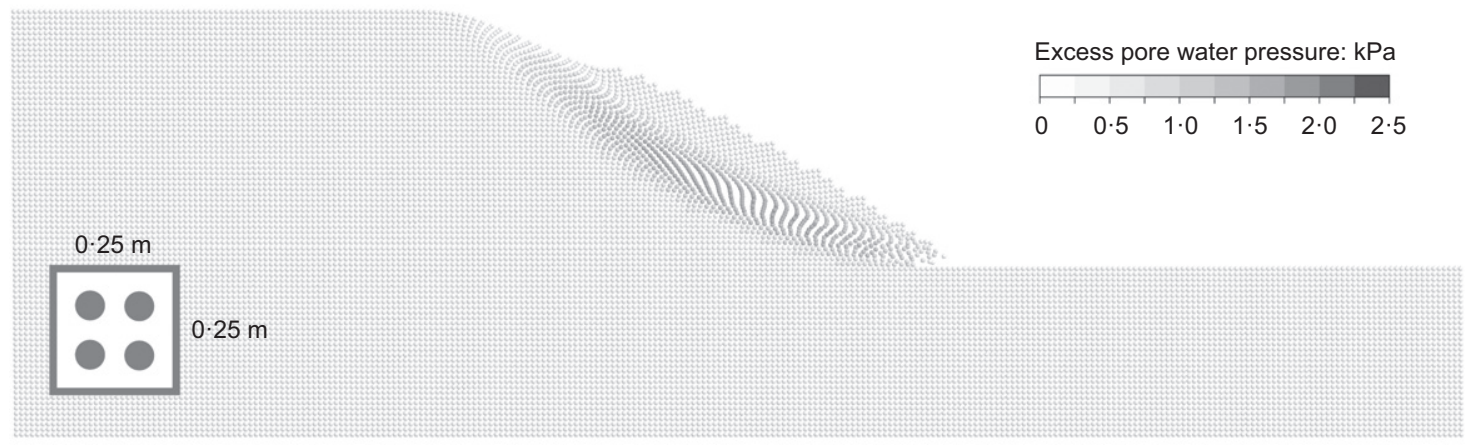

(b)

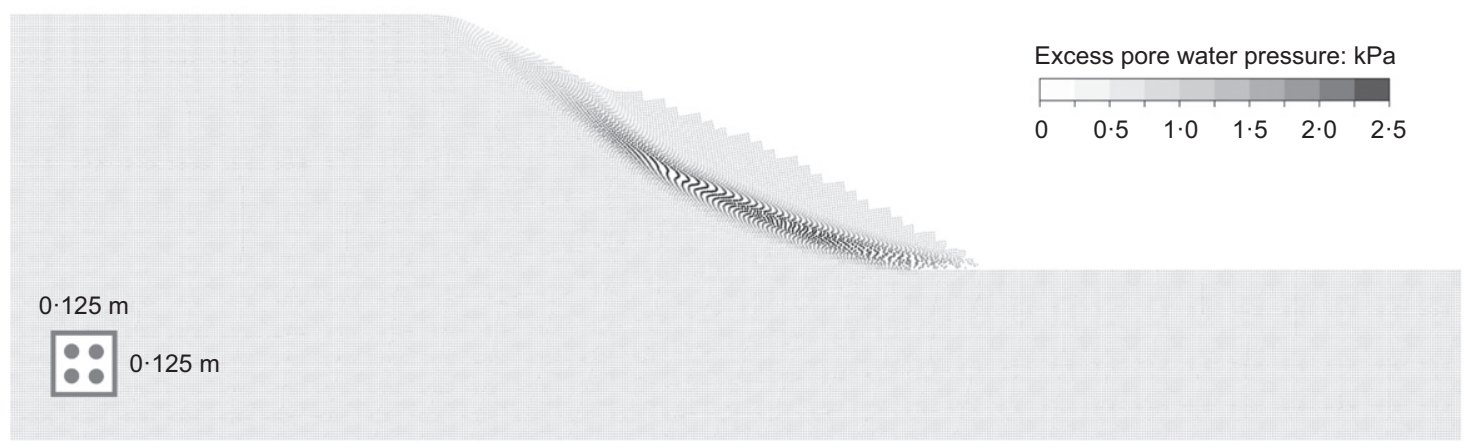

(c)

Fig. 8. Excess pore water pressure at the end of the motion calculated for the reference case for a permeability value of $K=10^{-11} \mathrm{~m} / \mathrm{s}$ and for different sizes of mesh elements (indicated in the figure)

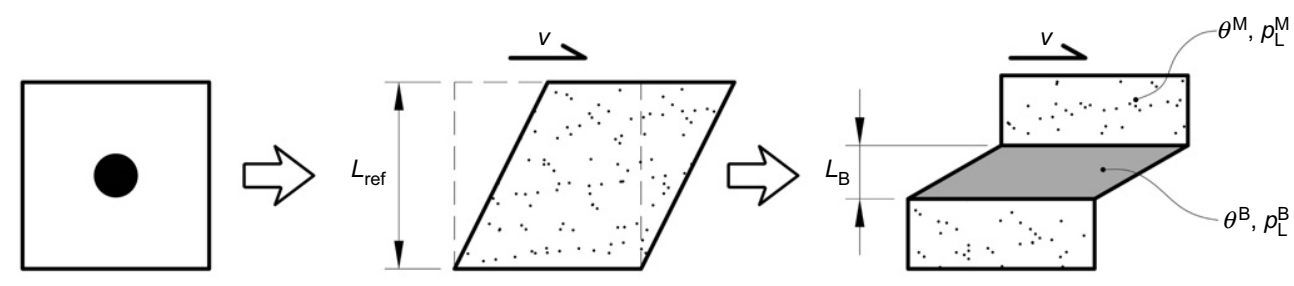

Volume of reference

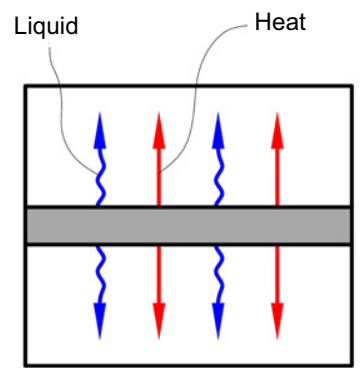

Fig. 9. Schematic representation of embedded shear bands generated 
interchanged, leads to

$$
\psi_{\theta}=\frac{\Gamma}{A_{\text {ref }}}
$$

Computations run for the reference case described below to show the effect of varying $A_{\text {ref }}$ from $A_{\text {ref }} / 4$ to $4 A_{\text {ref }}$ resulted in minimum changes in results.

In equation (20), convective and advective terms are defined exclusively at the matrix scale to impose that the interaction between embedded elements and matrix are defined locally at the scale of the reference volume.

The heat source term, $\dot{H}^{\mathrm{B}}$, included in the heat mass balance equation of the band, is supplied by energy generated into the embedded shear band. It is made equal to the frictional work rate dissipated assuming that the plastic strains localise in the shear band

$$
\dot{H}^{\mathrm{B}}=\sigma: \dot{\varepsilon}^{\mathrm{p}} \frac{L_{\mathrm{ref}}}{L_{\mathrm{B}}}
$$

The effective stress controlling the constitutive behaviour will be governed by the maximum value of liquid pressure prevailing in the embedded elements or in the matrix because they occupy the same position of the material point under consideration

$$
\boldsymbol{\sigma}^{\prime}=\boldsymbol{\sigma}-\max \left(p_{\mathrm{L}}^{\mathrm{B}}, p_{\mathrm{L}}^{\mathrm{M}}\right) \mathbf{m}
$$

\section{SENSITIVITY ANALYSIS: EFFECT OF MESH SIZE, SHEAR BAND THICKNESS AND PERMEABILITY}

The reference case evaluated previously using different element sizes is analysed again including the embedded shear band with the aim of evaluating the capabilities of the methodology. In all the cases analysed, embedded shear bands are generated at those elements in which the computed plastic deviatoric strain is different from zero. The distribution of excess pore water pressure and maximum displacement is plotted in Figs 10 and 11. The effect of the mesh size is observed in minor details of the plots. However, the pathological dependence on the shear band thickness has been removed. In fact, the calculated maximum pore pressure in the shearing band (Fig. 10) and the displacement (Fig. 11) are the same. In the three cases analysed, an embedded shear band thickness $L_{\mathrm{B}}$ of $1 \mathrm{~cm}$ was introduced as an input parameter.

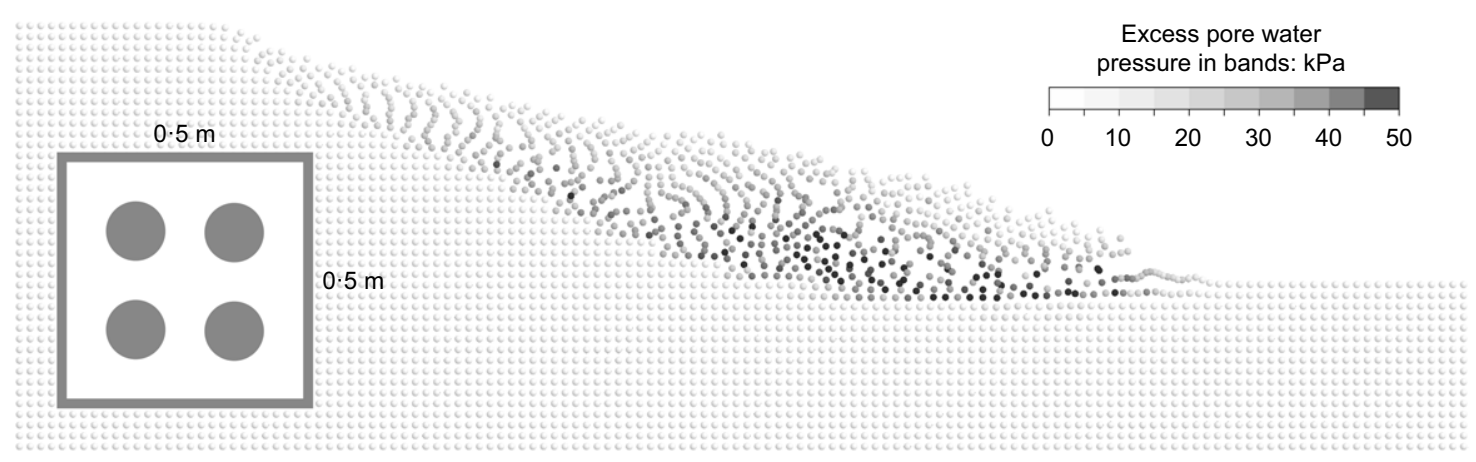

(a)

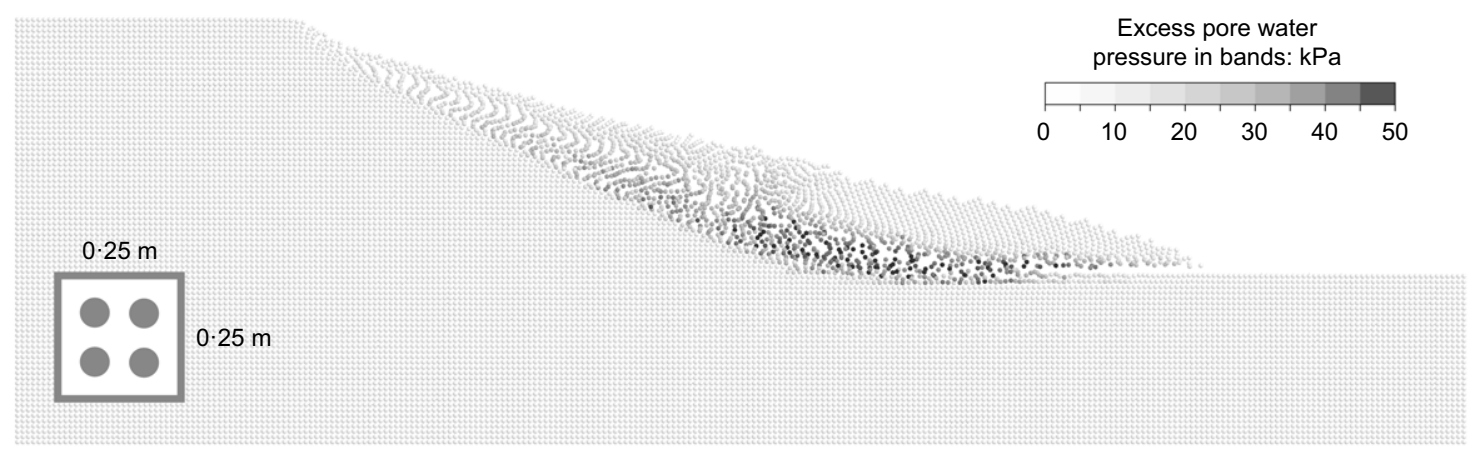

(b)

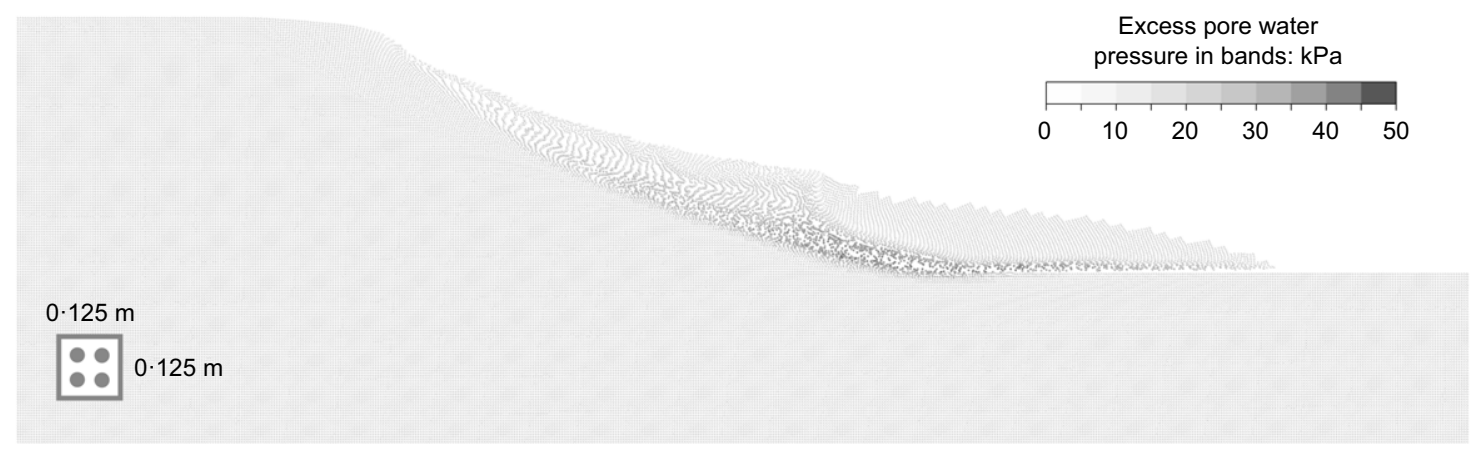

(c)

Fig. 10. Excess pore water pressure at the end of the motion calculated for the reference case, including embedded shear bands, for a permeability value of $K=10^{-11} \mathrm{~m} / \mathrm{s}$ and for different sizes of mesh elements: (a) $0.5 \times 0.5 \mathrm{~m}$; (b) $0.25 \times 0 \cdot 25 \mathrm{~m} ;(\mathrm{c}) 0 \cdot 125 \times 0 \cdot 125 \mathrm{~m}$ 


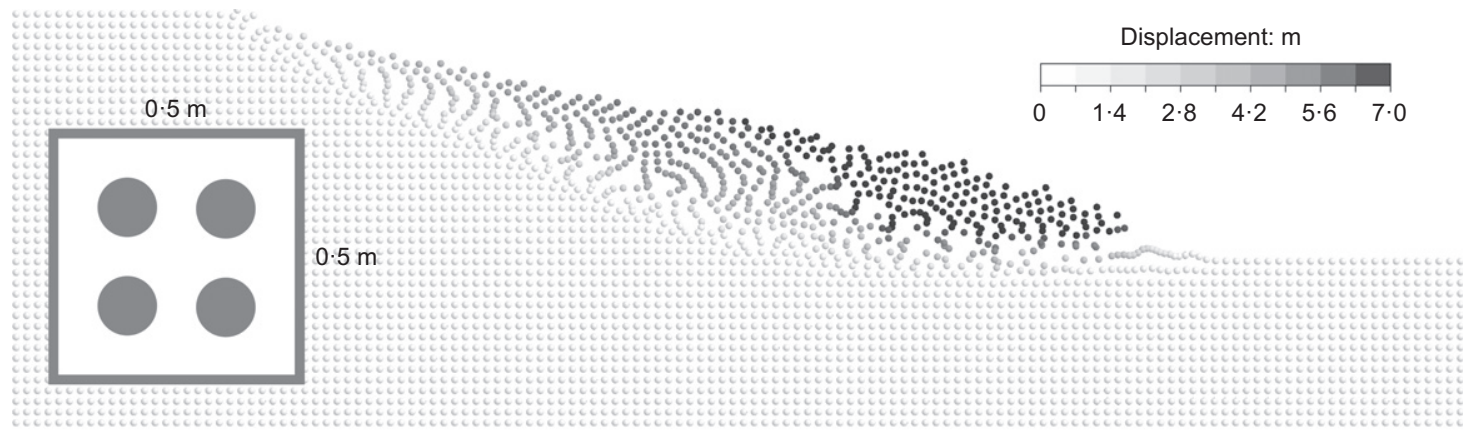

(a)

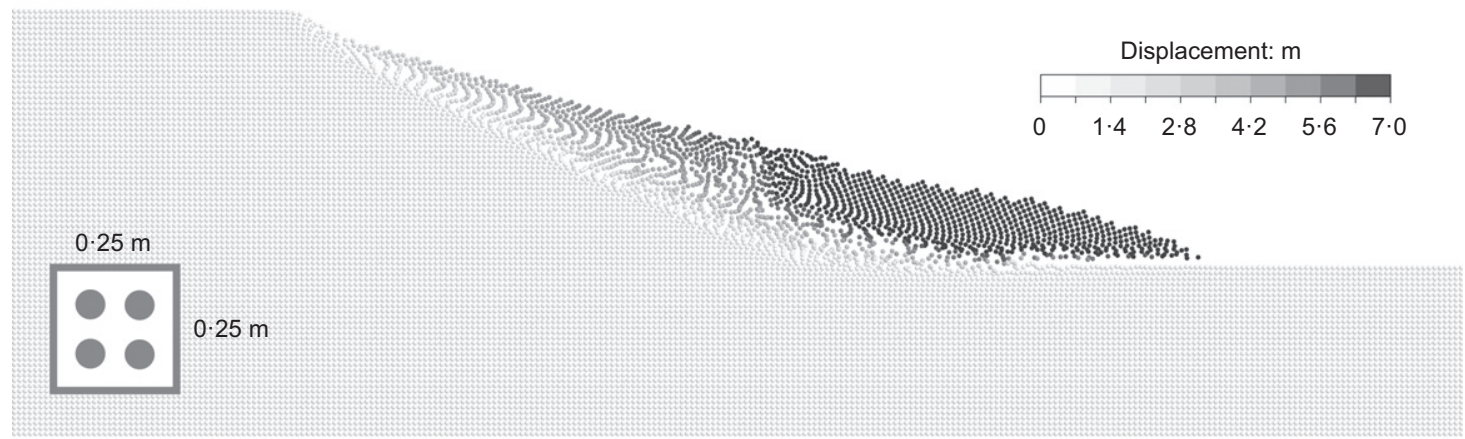

(b)

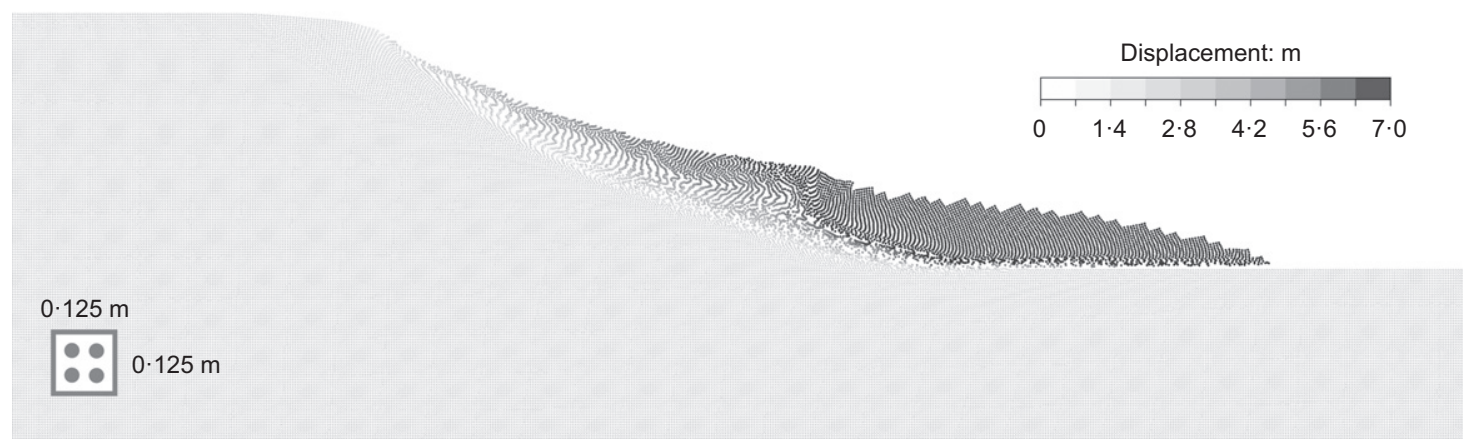

(c)

Fig. 11. Maximum displacement calculated for the reference case, including embedded shear bands, for a permeability value of $K=10^{-11} \mathrm{~m} / \mathrm{s}$ and for different sizes of mesh elements: (a) $0.5 \times 0.5 \mathrm{~m}$; (b) $0.25 \times 0.25 \mathrm{~m}$; (c) $0.125 \times 0125 \mathrm{~m}$

The effect of the shear band thickness is shown in Fig. 12 in terms of maximum displacement. Band thicknesses varying between $10 \mathrm{~cm}$ and $0.5 \mathrm{~cm}$ are evaluated. Thinner shear bands lead to higher values of thermally induced pore water pressure and the associated reduction of the shear strength results in higher values of maximum velocity and displacement.

The effect of the permeability is now evaluated. In all the cases evaluated, $L_{\mathrm{B}}=1 \mathrm{~cm}$. Fig. 13(b) shows the evolution of displacements of a point located initially at the surface in the middle of the slope (Fig. 13(a)) for different values of permeability ranging from $10^{-3} \mathrm{~m} / \mathrm{s}$ to $10^{-11} \mathrm{~m} / \mathrm{s}$. Fig. $13(\mathrm{c})$ shows the calculated pore pressure records on a central point of the sliding surface. Zero values of pore water pressure are calculated in the most pervious case $\left(K=10^{-3} \mathrm{~m} / \mathrm{s}\right)$. When permeability decreases to $K=10^{-5} \mathrm{~m} / \mathrm{s}$, low values of excess pore pressure are accumulated. For $K=10^{-7} \mathrm{~m} / \mathrm{s}$ pore pressure initially increases, to reduce during the motion. As the values of permeability decrease further, the maximum velocity and the displacements increase due to additional excess pore water pressure accumulating in the shear band (Fig. 13(b)).

The distributions of plastic strains, excess pore water pressures and temperature for the case of $K=10^{-11} \mathrm{~m} / \mathrm{s}$ are plotted in Fig. 14. The shear strain increments localise in a band affecting one or two elements of the computational mesh. The generation of the excess pore water pressure concentrates at those elements and, due to their low permeability and the short time of the motion, pore pressure does not dissipate.

Temperature increments are generated in all cases as a consequence of the frictional work dissipated during the motion (Fig. 14(c)). Calculated temperature increments are small, but their effect is significant because of the induced changes in thermal dilation coefficient of water and solids.

\section{VAJONT LANDSLIDE \\ Model description}

The model developed here departs significantly from the analysis described in previous publications listed in the introduction. Alonso et al. (2016) compares the modelling approaches of previous contributions and refers to a few topics: problem formulation, sliding geometry and constitutive modelling. The analysis described here is no longer based on the 1D approximation for thermo-hydro-mechanical processes in the vicinity of the shear band, the geometry respects the geological conditions of the case and the 


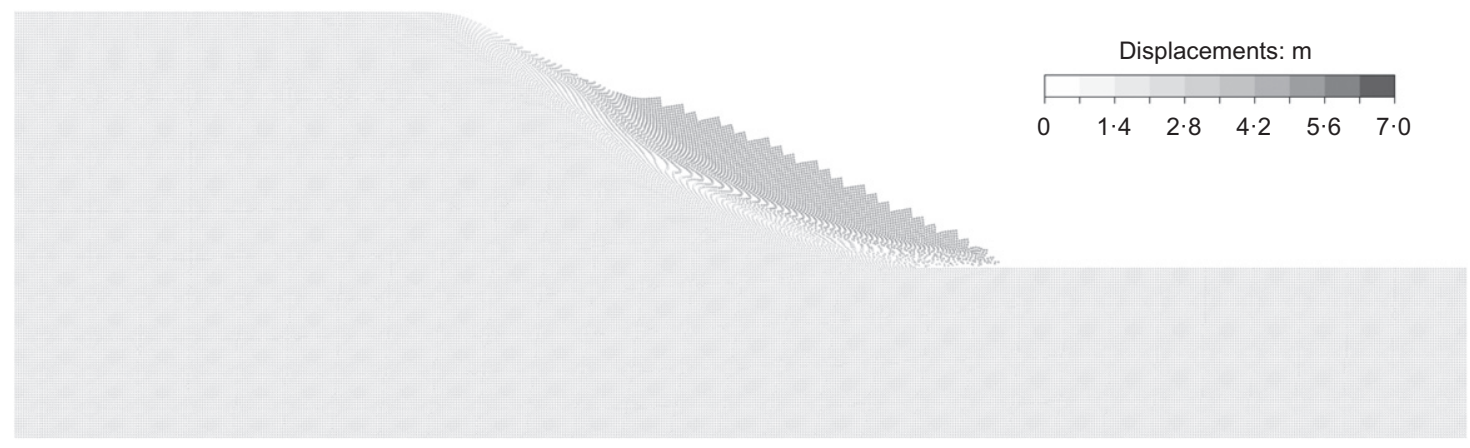

(a)

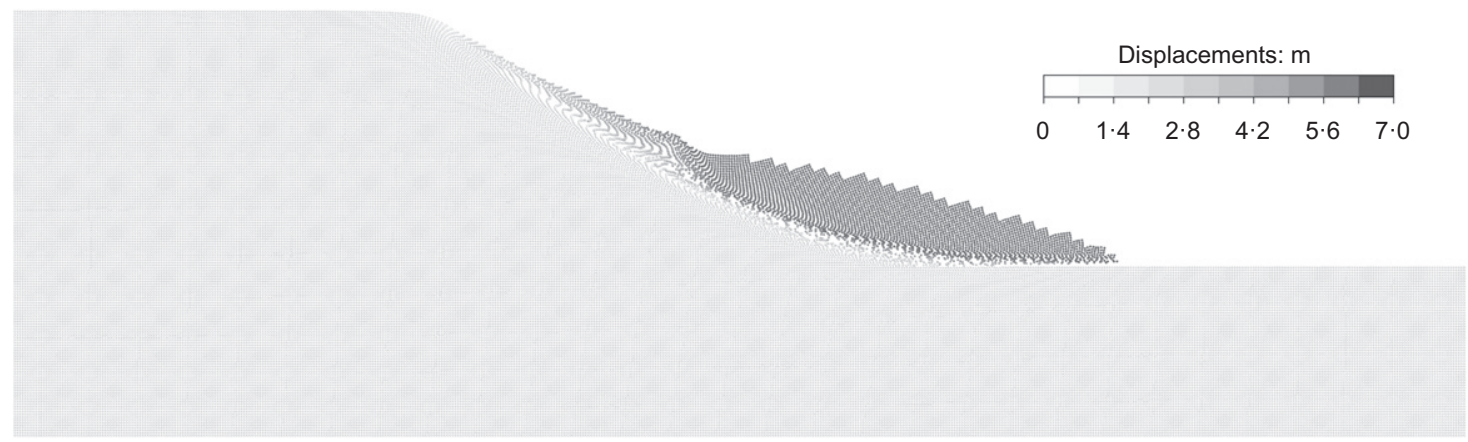

(b)

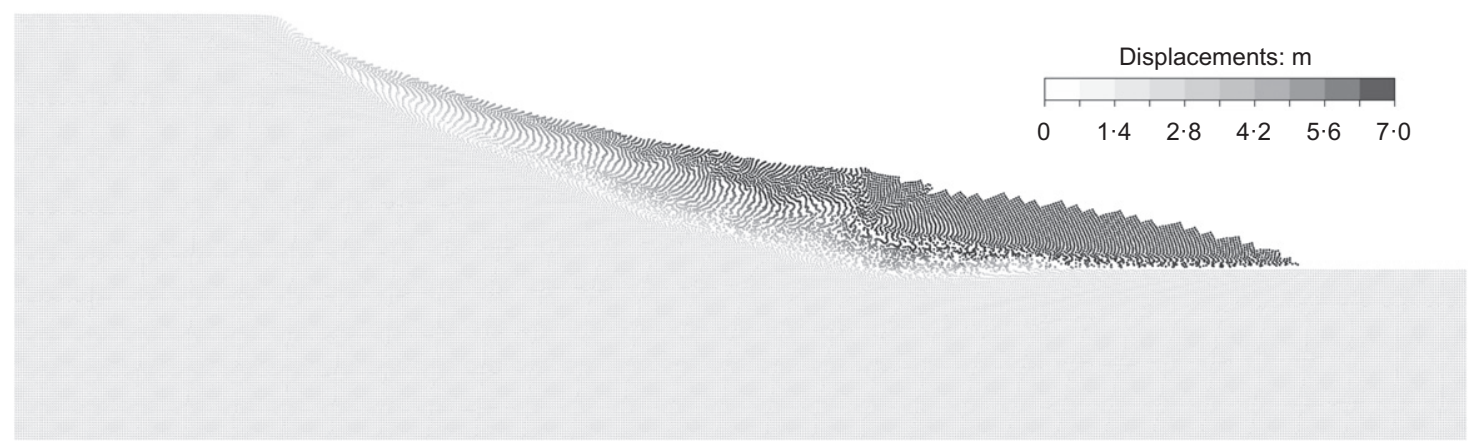

(c)

Fig. 12. Maximum displacement calculated for the reference case for a permeability value of $K=10^{-11} \mathrm{~m} / \mathrm{s}$ and for different values of shear band thickness: (a) $10 \mathrm{~cm}$; (b) $5 \mathrm{~cm}$; (c) $0.5 \mathrm{~cm}$

failure mechanism and landslide geometry are not imposed 'a priori'. There was an interest in checking if this generalisation could reproduce the Vajont accelerated motion.

The landslide trigger was the elevation of the water level in the reservoir. The impoundment of the reservoir is modelled as a continuous increase in water level. Modelling the creeping stage prior to the failure would involve the consideration of additional features. In particular, Veveakis et al. (2007), Alonso \& Pinyol (2012) and Alonso et al. (2016) invoked rate effects on the strengthening of the behaviour of the material located in the basal surface to explain the slow motion observed in Vajont slope. In addition, the internal shearing of the mobilised mass during the motion, discussed in Alonso \& Pinyol (2010) and Yerro et al. (2016a, 2016b), probably had an important role, which contributed to maintain the slope at a slow motion. These aspects are outside the scope of this paper, which focuses on the thermal pressurisation phenomenon and its consequences on the landslide run-out.

The 2D section selected for the analysis (Fig. 15) follows the cross-section proposed by Hendron \& Patton (1985). The mobilised mass is characterised by a unique homogeneous rock whose behaviour is defined by the strain-softening Mohr-Coulomb model defined in the earlier section 'Thermo-hydro-mechanical MPM formulation for saturated soils'. In the MPM model, the rock was defined by a $c_{\text {peak }}^{\prime}=2800 \mathrm{kPa}$ and $\phi_{\text {peak }}^{\prime}=43^{\circ}$ and $c_{\text {res }}^{\prime}=200 \mathrm{kPa}$ and $\phi_{\text {res }}^{\prime}=34^{\circ}$. The softening shape factor selected $(\eta=100)$ leads to a drop in strength from peak to residual value in $30 \mathrm{~mm}$ of relative displacement. The selected values are accepted as a rough average approximation of the complex stratification of limestone and marl layers (Semenza, 2001) with different degrees of fracturing. They are also consistent with the range of average strength parameters suggested by Alonso \& Pinyol (2010) for the Vajont rock above the sliding surface. A porosity equal to $n=0 \cdot 2$, a Young's modulus $E=5000 \mathrm{MPa}$ and a Poisson coefficient $v=0.33$ were estimated for the rock mass.

The model is able to simulate the progressive failure along shearing planes of the rock. This is expected because the kinematics of the motion force internal shearing of the rock in the direction crossing the sedimentary surfaces at high angles. This is shown in the plots of shearing bands given 


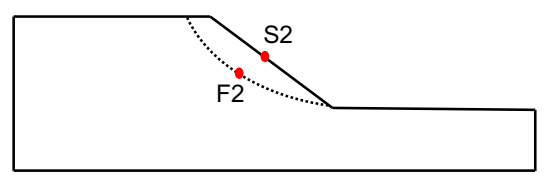

(a)

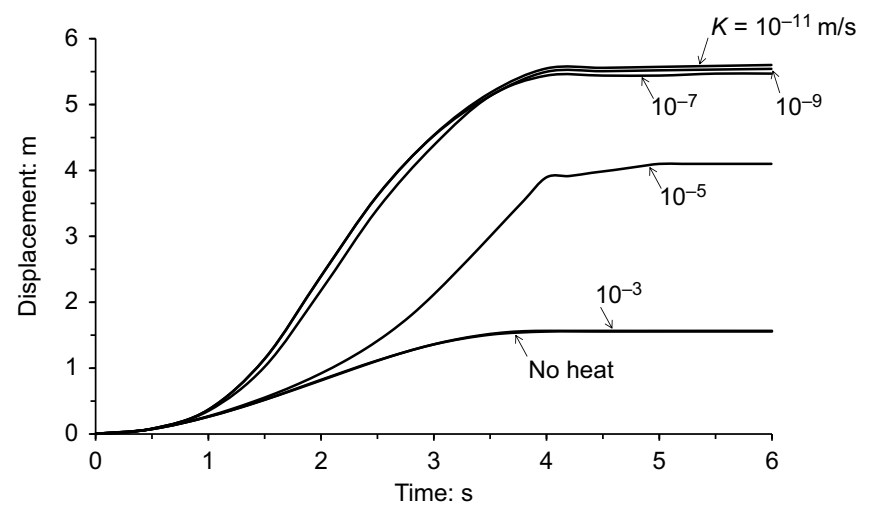

(b)

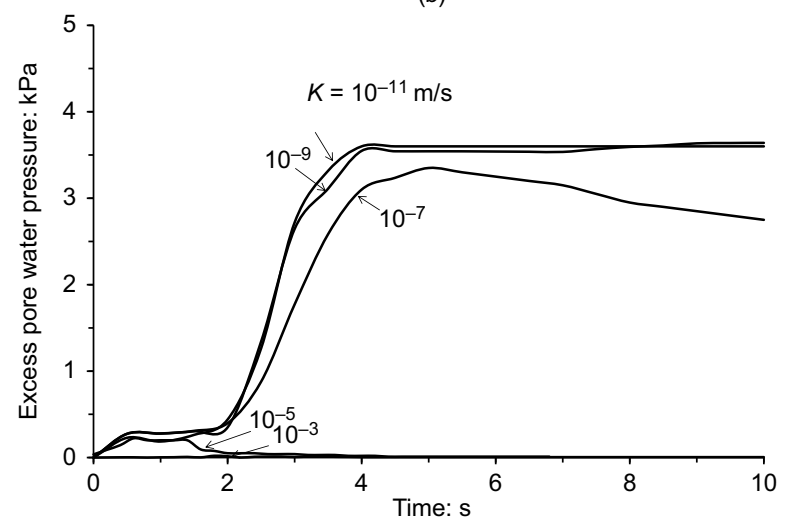

(c)

Fig. 13. (a) Position of points analysed. (b) Displacement of point S2 and (c) excess pore water pressure evolution of point $\mathrm{F} 2$ for the reference case and different values of saturated permeability, $K$

below. This internal shearing was also discussed in Alonso \& Pinyol (2010) and Yerro et al. (2016a, 2016b). Yerro et al. (2016a, 2016b) found that a unique sub-vertical shear band develops from the sharp kink defined by the two planar basal sliding surfaces. This band acts as a rock degradation mechanism as the slide moves forward. A progressive failure develops along the shear band during all stages of motion. It was also shown that the internal development of shearing bands in the rock mass is controlled by the geometry of the basal sliding surface. Progressive failure of the brittle rock mass alone was not capable of explaining the high sliding velocities of the slide. An apparent basal friction angle of $0^{\circ}$ was required to match the high velocities of the slide.

A significant aspect of the analysis is the nature of the basal sliding surface. In their comprehensive report, Hendron \& Patton (1985), even if they accept the dominant role of the residual clay strength, recognise the existence of areas in which shearing was across bedding planes, the presence of sections not having clay, of areas where the clay was squeezed into rock voids and of brecciated rock fragments within the clay beds. Paronuzzi \& Bolla (2015) characterised the basal 'detachment' surface by a stepped pattern involving a variety of materials: limestone and marly limestone strata, clay interbeds, clay lenses and angular gravels. Wolter et al. (2014) describe in detail the basal surface by means of terrestrial photogrammetry.
The exposed surface is characterised by a complex geometry of undulations and ridges which probably entered into rock-to-rock contact during sliding. They introduce four roughness classes to describe the sliding surface. They conclude that in some areas the asperities would imply the shearing of rock mass or a dilatant behaviour. Fig. 16 shows the aspect of the basal surface in the spring of 2007, immediately above the displaced rock mass. Some of the features mentioned can be observed in the photographs. The set of observations summarised above indicate that the basal sliding motion was far from being a smooth planar uniform shearing across a layer of clay. Rock shearing and rock-to-rock friction was present during the landslide.

The available information is not enough to adopt a precise model of the basal surface and it was decided to represent it by a number of brittle rock bridges separated by clay areas (Fig. 15). The rock bridges were characterised by the rock properties adopted for the sliding rock mass.

Residual strength of the high-plasticity clay of the basal surface measured in shearing tests (Hendron \& Patton, 1985; Tika \& Hutchinson, 1999; Ferri et al., 2010, 2011) suggests a value of $11^{\circ}$ for the residual friction angle. A low permeability $\left(K=10^{-11} \mathrm{~m} / \mathrm{s}\right)$ was adopted for the clay in view of its high plasticity.

The underlying stable bedrock below the clayey layer was given the same properties as the overlying rock. This material is also present in the opposite valley slope. The river canyon on the bottom of the valley was not represented. The calculations indicated that the failure surfaces did not affect the lower boundary rock because of the significantly lower strength of the clayey layer with respect to the rest of the rock. Therefore, the thickness of the material below the clayey layer is small in order to reduce the dimension of the model and the computational cost.

The model also includes the reservoir water as an elastic material characterised by its real volumetric compressibility coefficient and imposing a shearing modulus close to zero. This procedure allows application of the weight of the water and the corresponding water pressure on the slope surface at the initial time and also during the motion. The dynamic water forces induced during the motion are also included automatically in the calculation. This is a better option than imposing the effect of the reservoir water as a supporting force because these conditions should be applied on the slope surface, which is not fixed, and the position of the nodes or material points defining the slope surface are unknown 'a priori'.

Figure 15 also shows the computational mesh used, which defines the entire domain of the problem. Four materials points are initially distributed within the elements representing the materials. They are located at the corresponding integration points of a four-point Gaussian quadrature. The rectangular elements are $5 \times 5 \mathrm{~m}$. This size is limited by the computational cost of the calculation. Using such element size, it is not possible to define accurately the sedimentary layers of Vajont slope. The lower heterogeneous clayey layer was defined by four elements across its thickness. The purpose of this discretisation was to avoid a situation whereby inner elements of the clay band shared nodes with the hard rock material.

According to the discussion presented in the earlier section 'Embedded shear bands', the mechanical work dissipated in heat was scaled, within the embedded localisation bands, by assuming a reference clay band thickness of $3 \mathrm{~cm}$. No excess pore pressures were allowed in the rock material because of its high permeability.

The initial stress state is the result of applying the gravity loading. 


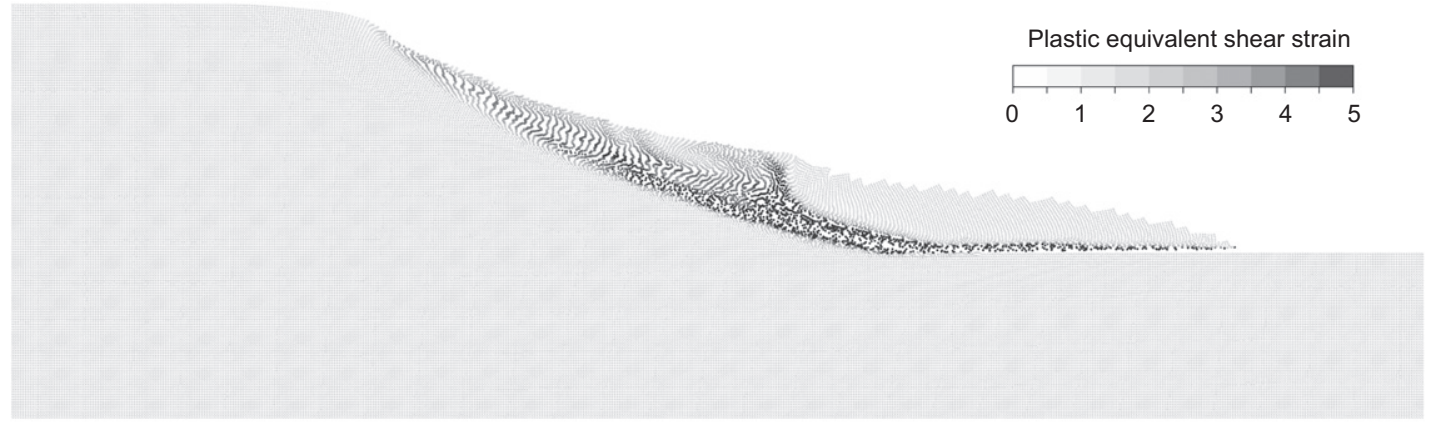

(a)

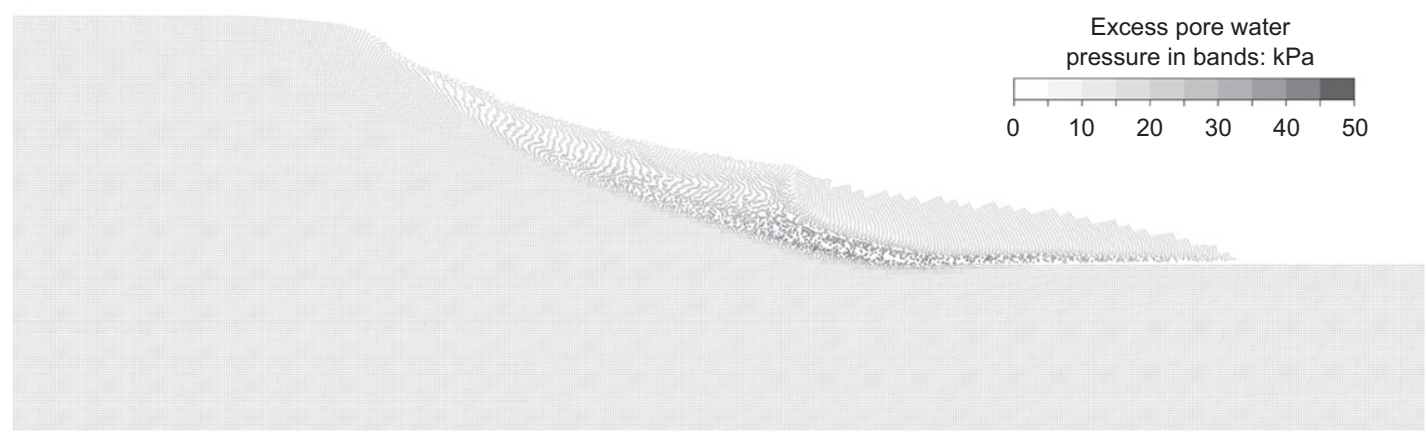

(b)

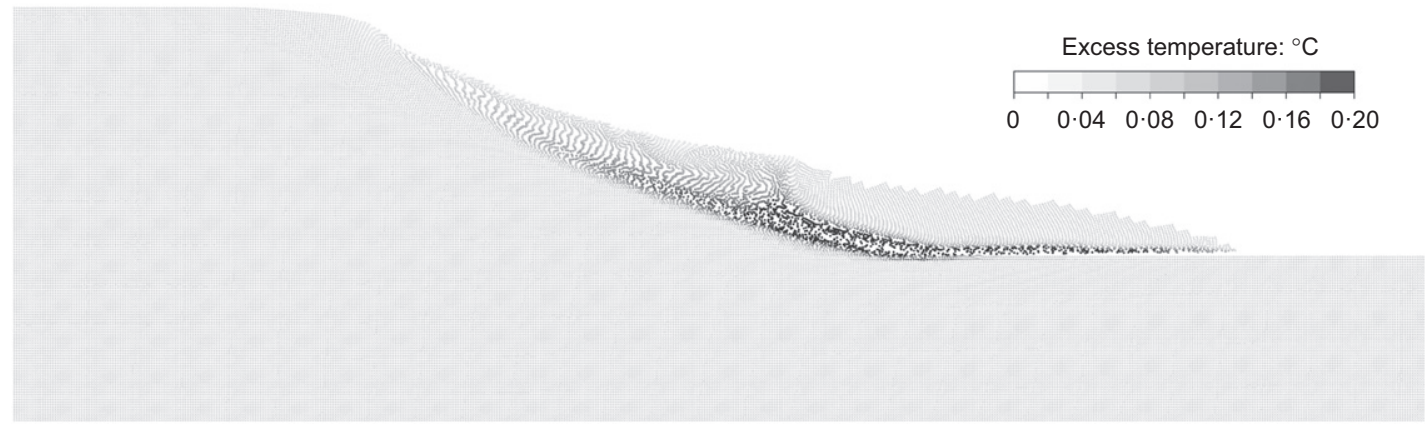

(c)

Fig. 14. Distribution of (a) accumulated deviatoric plastic strains, (b) excess pore water pressures and (c) temperature for the reference case at the end of the motion. Saturated permeability $K=10^{-11} \mathrm{~m} / \mathrm{s}$ and shear band thickness of $1 \mathrm{~cm}$

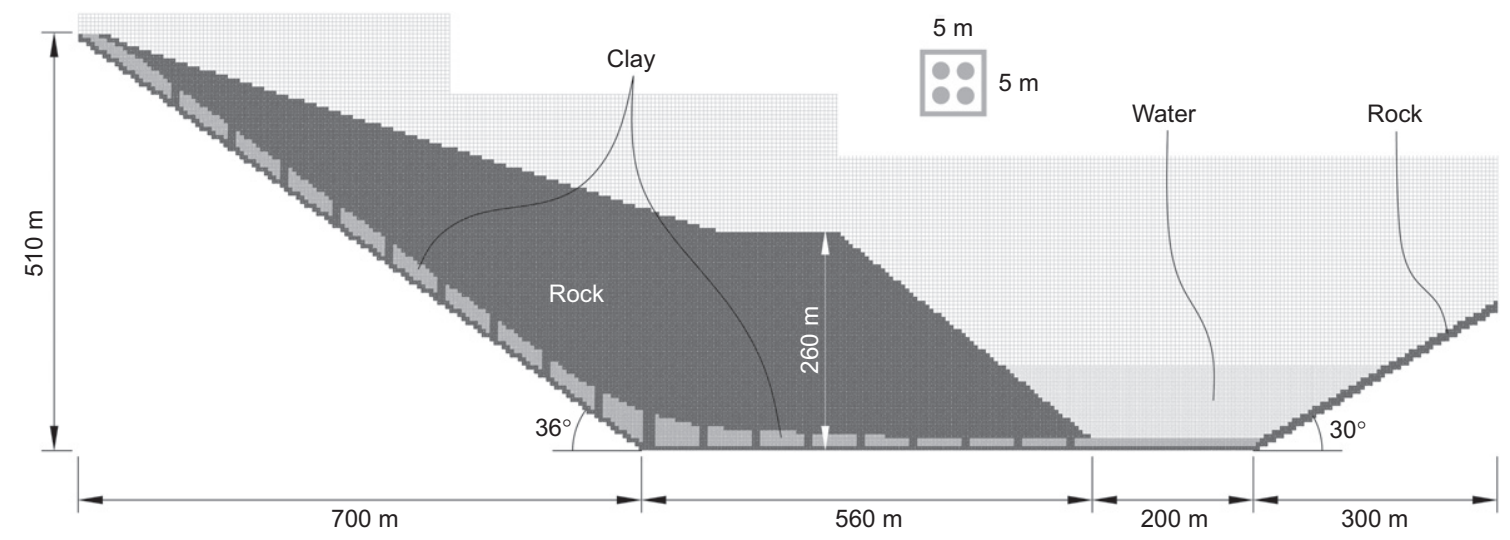

Fig. 15. Computational model, mesh and initial distribution of material points

\section{Numerical results}

The application of weight before the rise of the reservoir level leads to the mobilisation of the strength of the clay material as shown in Fig. 17(a), where the equivalent plastic shear strains are plotted. The slope remains in static equilibrium thanks to the strength provided by the rock bridges and rock mass. The increase of the water reservoir level leads to the rise of pore water pressures on the sliding surface. The supporting action of the water is also accounted for. Failure initiates when the water level is $100 \mathrm{~m}$ above 

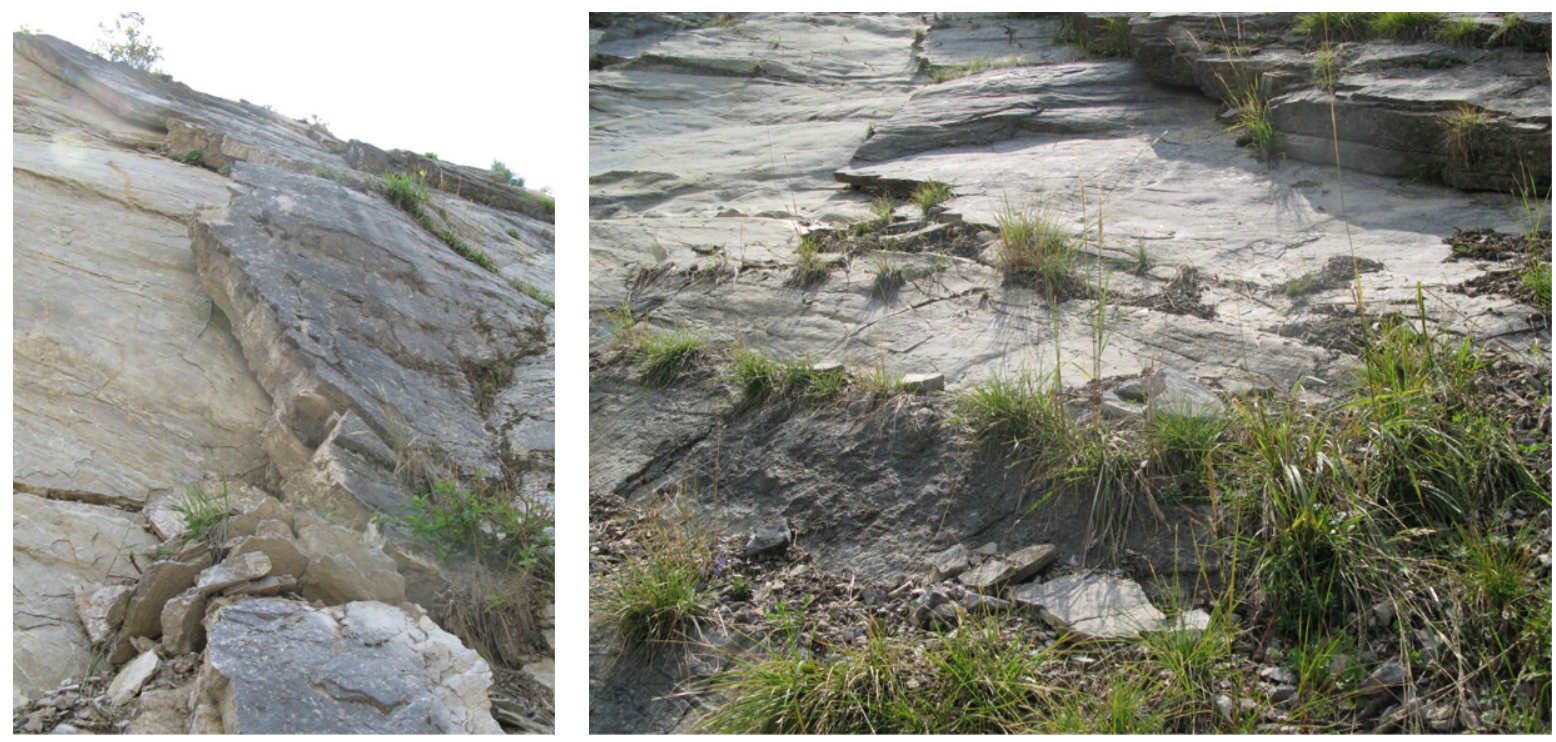

Fig. 16. Exposed basal surface of Vajont landslide in 2007. Photographs taken in the lower part of the exposed sliding surface

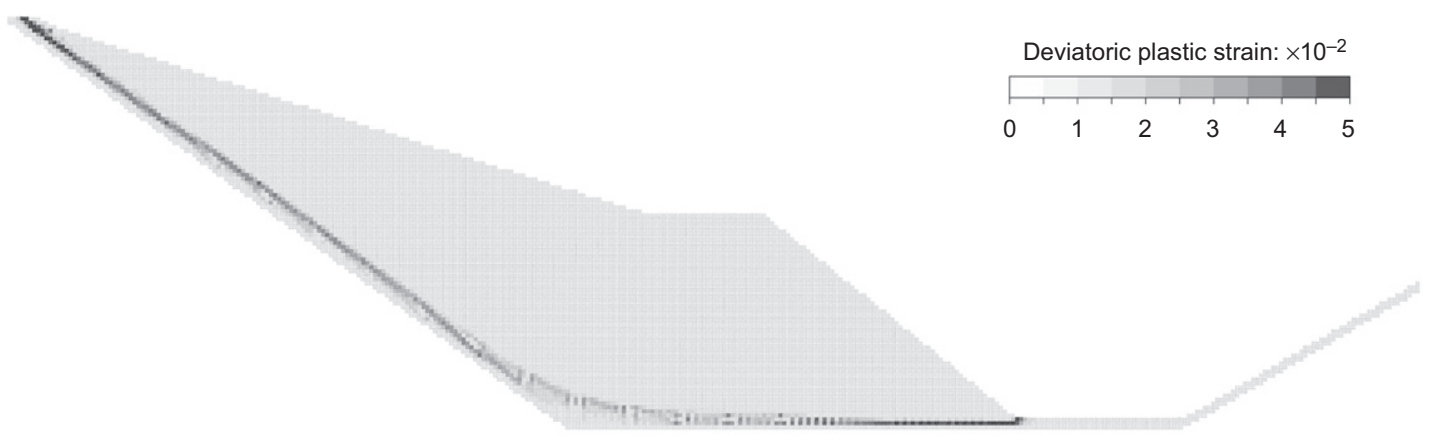

(a)

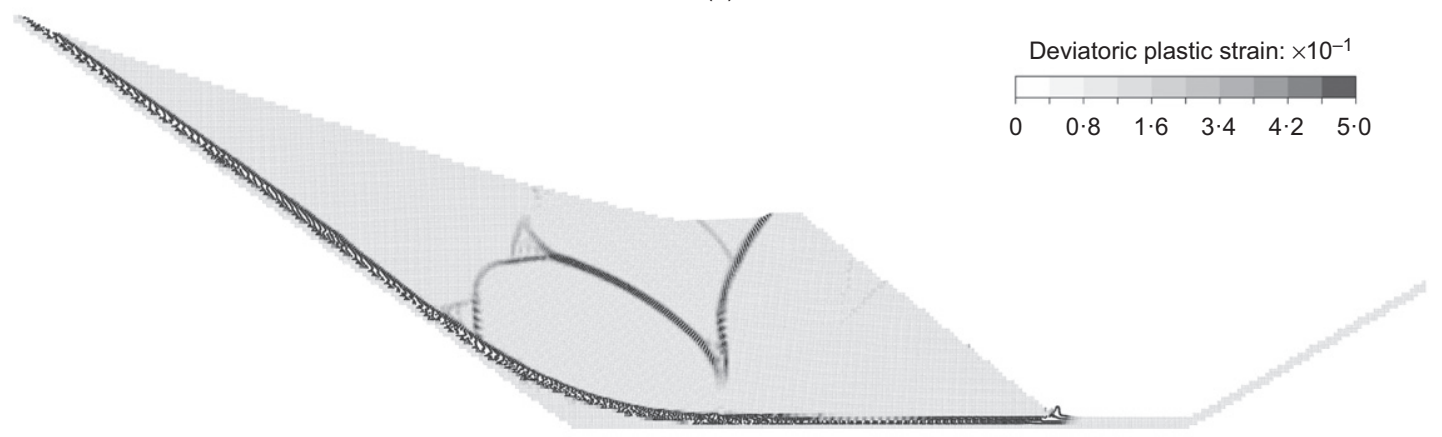

(b)

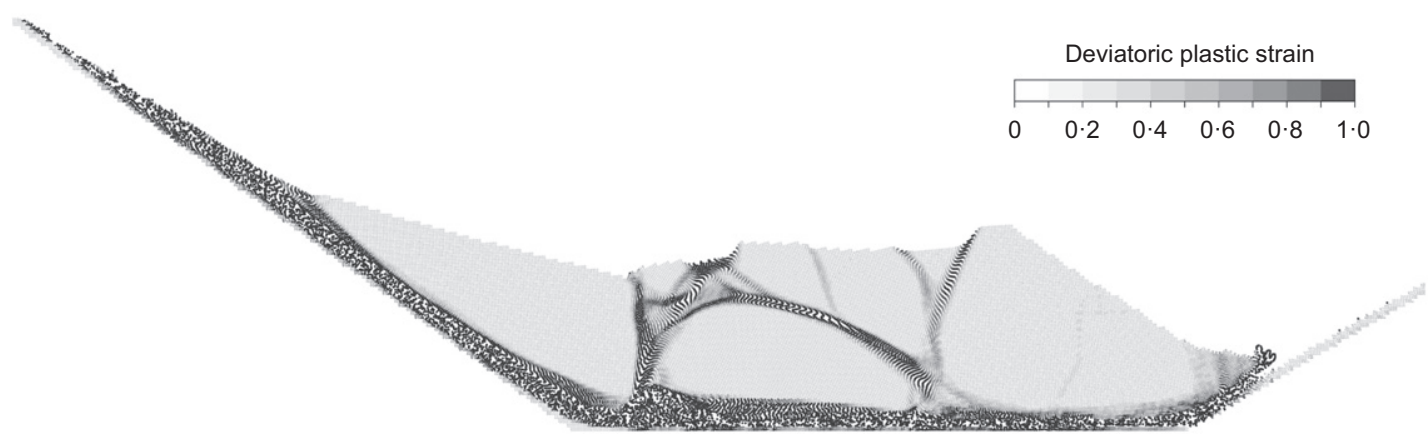

(c)

Fig. 17. Equivalent plastic shear strain: (a) before reservoir impoundment upon application of gravity loading; (b) at the initiation of the motion when reservoir level is at $100 \mathrm{~m}$; (c) at the end of the motion 
the toe. It corresponds to the elevation $700 \mathrm{~m}$ according to the cross-section 2 from Hendron \& Patton (1985). At this time, equivalent plastic shear strains localise, as shown in Fig. 17(b). Shear surfaces grow from the basal sliding surface at those points where the geometry of the sliding surface, conditioned by the geometry of the clay layer, exhibit a change in curvature. In fact, the infinite curvature radius of the planar sliding surfaces reduces to a radius of approximately $200 \mathrm{~m}$ in the curved zone around the kink created at the junction between the planar surfaces. The localised shear bands are curved and tend to join inside the rock mass. The associated strain softening results in a weak fracture surface which is visible in the plots of Figs 17 and 19.

The damage experienced by the rock mass at the end of the motion, once the landslide recovers a new static equilibrium, is shown in Fig. 17(c). Fig. 18 shows the displacement and velocity records calculated as the average of several materials points located in the five elements of the computational mesh forming the landslide toe. The maximum velocity reached by the landslide was reported by several authors. Müller (1964) mentions 25 to $30 \mathrm{~m} / \mathrm{s}$. Ciabatta (1964), cited by Nonveiller (1987), performed a dynamic analysis to find $17 \mathrm{~m} / \mathrm{s}$. Nonveiller (1987) calculates a maximum velocity of $15 \mathrm{~m} / \mathrm{s}$. Voight \& Faust (1982) in their pioneering contribution found a maximum velocity of $26 \mathrm{~m} / \mathrm{s}$ (for a planar geometry). Hendron \& Patton (1985) estimates values in the range $20-25 \mathrm{~m} / \mathrm{s}$. These are estimations based on a particular model for the dynamics of the motion and therefore they should be regarded as approximations to the actual field velocity. The maximum velocity calculated here $(20 \mathrm{~m} / \mathrm{s})$ fits into the set of values mentioned. The calculated run-out $(320 \mathrm{~m})$ is close, but somewhat smaller than other estimated values based on field observation (Hendron \& Patton, 1985).

Temperature, heat-induced pore water pressure increment and displacement distributions are given in Fig. 19.

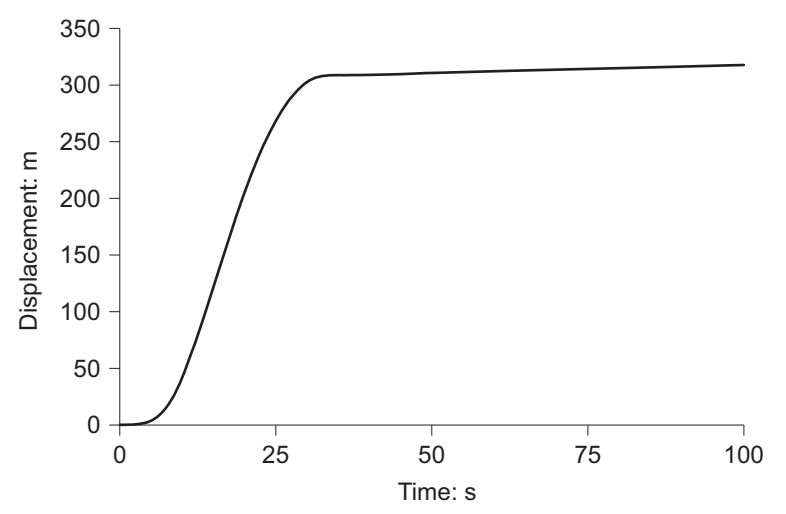

(a)

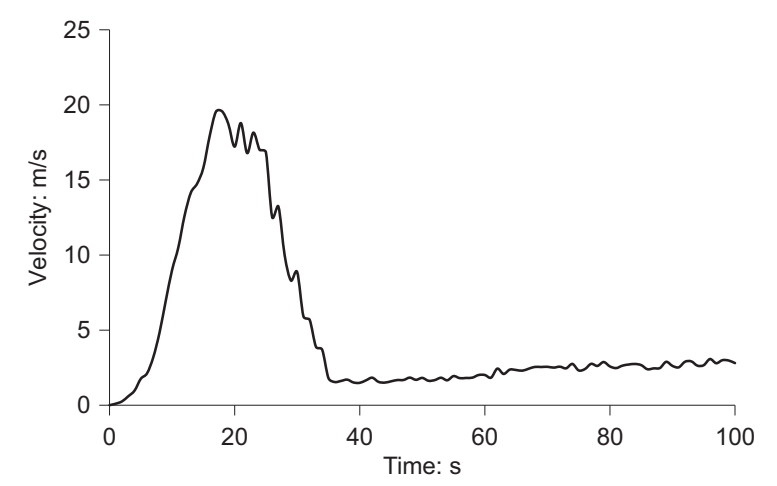

(b)

Fig. 18. Calculated (a) displacement and (b) velocity of Vajont landslide
Increments of temperature around $50^{\circ} \mathrm{C}$ are computed in the basal shear band. Maximum temperature increments of around $40^{\circ} \mathrm{C}$ are computed inside the rock mass. Excess pore water pressures concentrate in the impervious clayey soil where the work has been scaled. Pore water pressure dissipates outside the shear band affecting the rock overlying the clay layer. The presence of the pervious rock bridges accelerates the pore water pressure dissipation. Fig. 20 shows the calculated final positions of the landslide materials. What is actually plotted in the figure is the position of all material points. The basal clay layer has extended along most of the failure surface during the motion. In some places the clay has opened its way through the rock. Some field observations mentioned before (Hendron \& Patton, 1985; Paronuzzi \& Bolla, 2015) support this result. Note also that a horizontal layer of clay was located beyond the toe of the slide to avoid a direct rock to rock contact during the motion. Part of this clay was dragged by the landslide and is visible in Figs 17(c), 19 and 20.

\section{CONCLUSIONS}

This paper describes a general formulation to include the heat dissipated in irreversible shear deformations in a coupled hydro-mechanical framework. The problem is inspired by observations and past contributions in the field of landslides. The formulation is general and based on physical principles and therefore it has applicability to sliding deformation mechanisms. The formulation of the basic theory and the subsequent elaboration is a generalisation of previous contributions in the domain of fast landslides which describe the slide motion by means of a predetermined simple geometry characterised by blocks of bodies interacting at the boundaries through shearing surfaces. Furthermore, previous contributions formulate the necessary balance equations in a 1D space, perpendicular to the shearing surface. This limitation is also removed in the present analysis.

One difficulty of the model developed, which was numerically solved by means of an MPM approach, is the dependence of the results on the thickness of the shear bands developing in a failure scenario. In fact, the method predicts the generation of heat-induced excess pore water pressures in shear bands, which controls the available drained shear strength. Excess pore pressures dissipate in consolidation-like processes controlled by permeability, soil stiffness and shear band thickness. Permeability is the main controlling factor for pore water pressure and heat development, as well as for the resulting slide kinematics once failure is triggered. However, shear band thickness is also a critical parameter which depends on the size of elements and geometry of the computational mesh. Given the small thickness expected in shear bands in clayey soils, the appropriate computational mesh would become unrealistically dense. The effect of shear band thickness is first discussed with the help of a simple sliding model, which was solved analytically.

A 2D plane strain MPM analysis of the failure of a reference simple slope illustrates the significant effect of mesh size in the results. The procedure described in the paper to solve the shear band thickness issue is to embed a ubiquitous set of shear bands into the material domain whenever plastic strains develop. These strains are assumed to be localised in a shear band whose thickness is selected in view of the material properties or other observations. A set of balance equations for the local transfer of liquid and heat is formulated to reproduce the expected physical phenomena in the vicinity of the shear bands. The procedure was successfully tested in a reference slope analysis. Excess pore pressures and slope deformation were found to be independent of mesh size. 


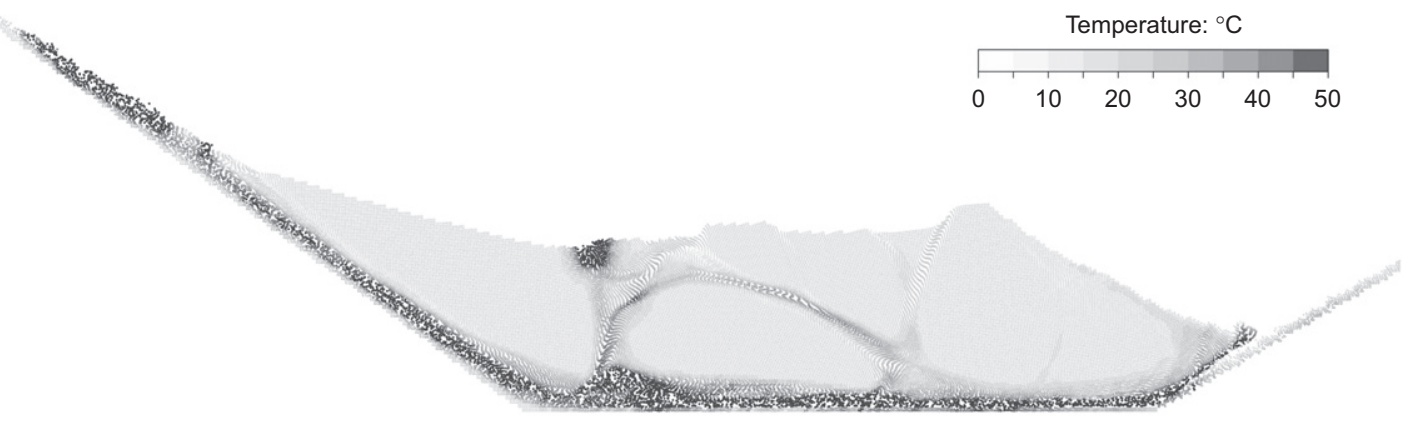

(a)

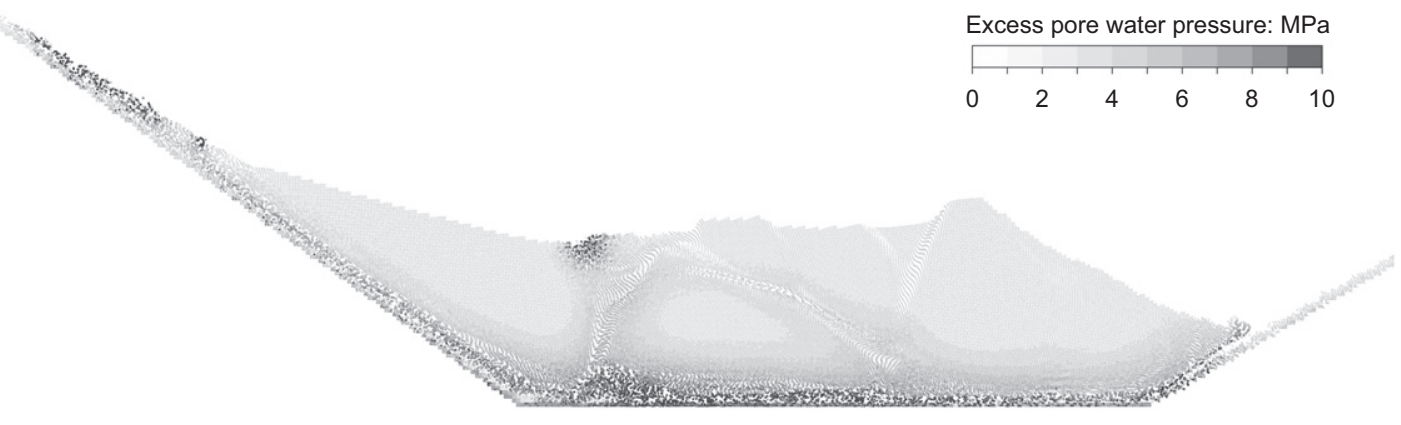

(b)

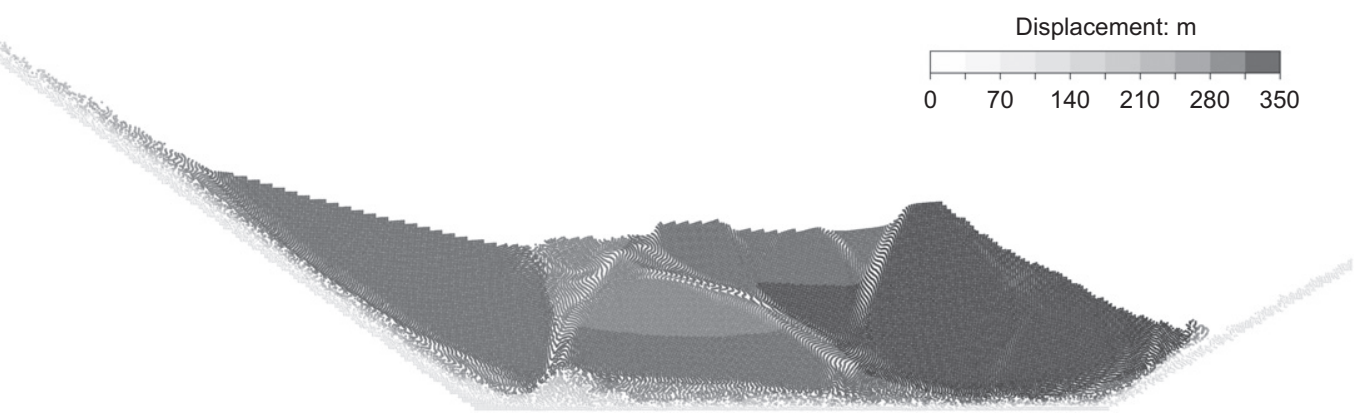

(c)

Fig. 19. (a) Temperature; (b) excess pore water pressures and (c) displacements at the end of the motion

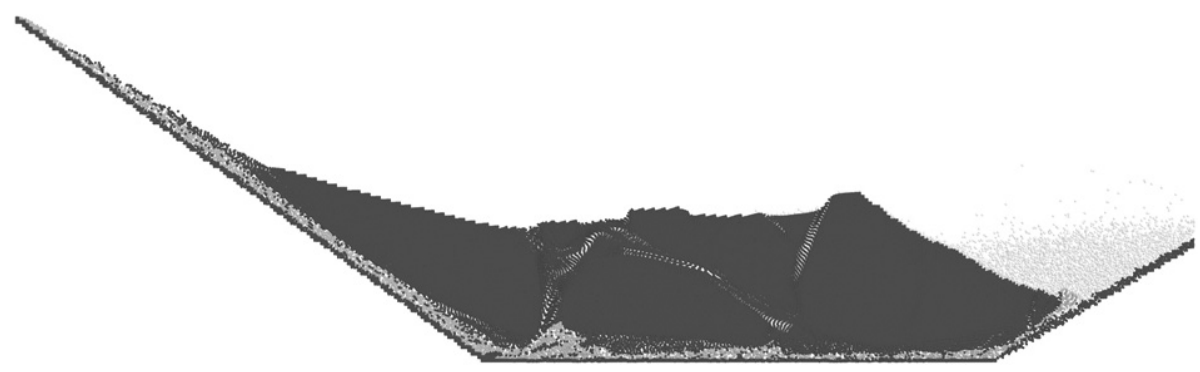

Fig. 20. Distribution of landslide materials at the end of the motion. The plot indicates the position of material points

The well-known Vajont case was selected as a real case to check the model. Vajont, for the purpose of calibrating the model, offers essentially two key items of information: the estimated sliding velocity and the run-out. The model built is based on a representative $2 \mathrm{D}$ cross-section. The geometry and rock parameters selected profit from previous work on the case and, also, on recent geological investigations. The rock mass above the basal clayey shearing zone was characterised by a brittle Mohr-Coulomb model. A residual friction angle $\left(11^{\circ}\right)$ was adopted for the basal high-plasticity clay. However, in view of recent descriptions of the complex nature of the shearing zone, a few 'rock bridges' were introduced in an effort to account for the complex geometry and heterogeneous materials involved.

In agreement with real conditions, the failure was triggered by a progressive elevation of the water level in the reservoir (which was also included in the model). Failure and the subsequent accelerated motion occurred at a water elevation 
close to the actual value. The calculated velocity and run-out also match well the estimated values reported in previous publications.

The model developed is believed to offer an advanced tool to systematically incorporate thermal effects into landslides modelling. It contributes to an increased understanding of phenomena leading to landslide acceleration after failure. The model is capable of reproducing the initial pre-failure state, the onset of failure and the subsequent motion. In the examples described and, notably, in the well-documented case of Vajont, a single set of material parameters is used.

\section{ACKNOWLEDGEMENTS}

The authors acknowledge the financial support to CIMNE by the CERCA Programme/Generalitat de Catalunya. The first and the second authors also acknowledge the fellowship IJCI-2015-26342 and scholarship BES-2014-068284 from the Spanish government, respectively. The fourth author has received funding from the European Union's Horizon 2020 research and innovation programme under the Marie Skłodowska-Curie grant agreement no. 645665 .

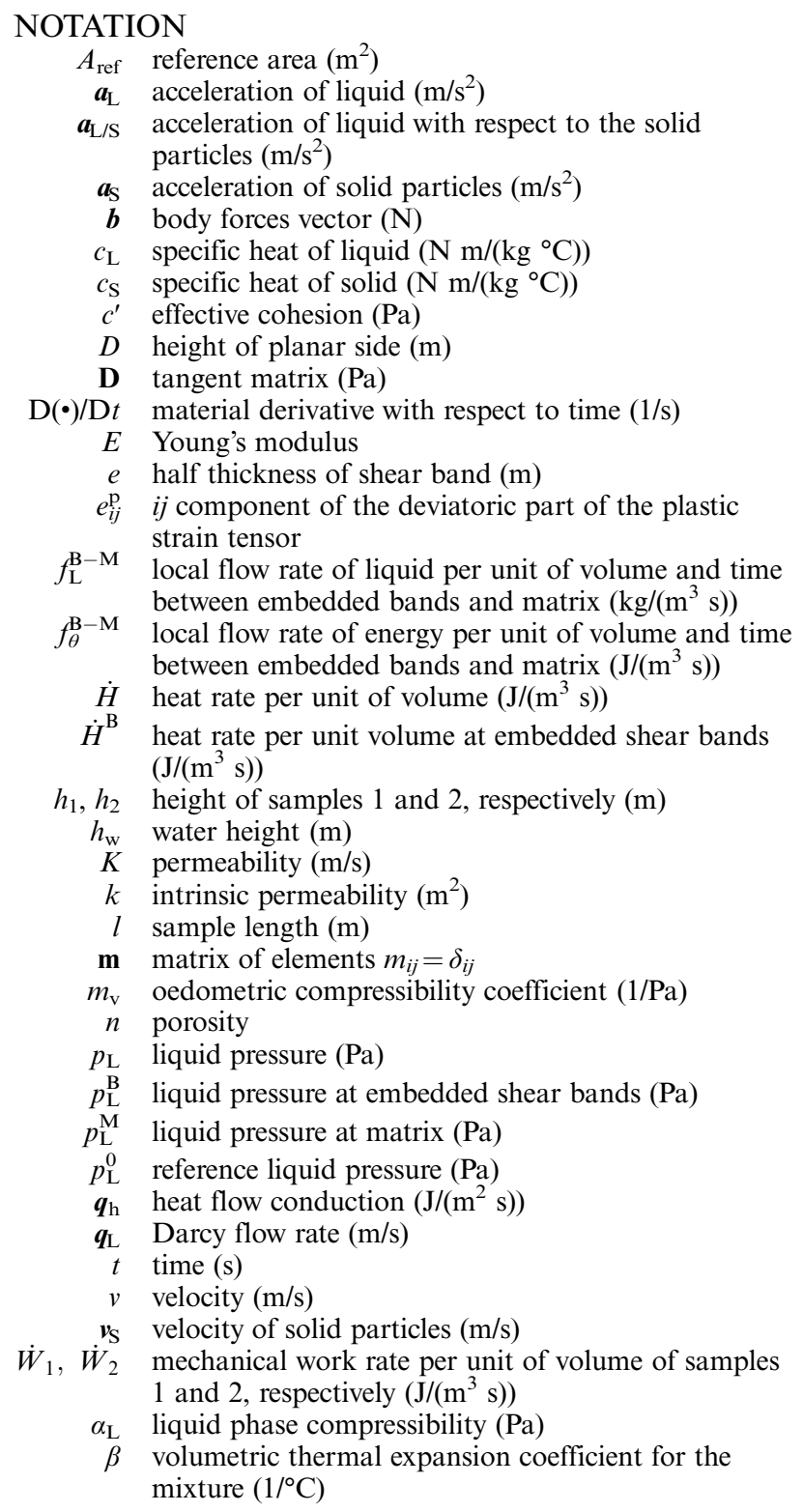

$\beta_{\mathrm{L}} \quad$ volumetric thermal expansion coefficient for liquid $\left(1 /{ }^{\circ} \mathrm{C}\right)$

$\beta_{\mathrm{S}} \quad$ volumetric thermal expansion coefficient for solid $\left(1 /{ }^{\circ} \mathrm{C}\right)$

$\Gamma \quad$ Fourier's thermal conduction coefficient $\left(\mathrm{J} /\left(\mathrm{m} \mathrm{s}^{\circ} \mathrm{C}\right)\right)$

$\gamma_{\mathrm{L}}$ specific weight of liquid $\left(\mathrm{N} / \mathrm{m}^{3}\right)$

$\dot{\gamma}_{1}, \dot{\gamma}_{2} \quad$ shear strain rate of samples 1 and 2, respectively (1/s)

$\dot{\delta}$ displacement rate $(\mathrm{m} / \mathrm{s})$

$\delta_{i j} \quad$ Kronecker delta

$\partial(\bullet) / \partial t$ partial derivative with respect to time $(1 / \mathrm{s})$

$\dot{\varepsilon}^{\mathrm{p}} \quad$ plastic strain rate tensor

$\eta \quad$ shape factor controlling strength softening

$\theta$ temperature $\left({ }^{\circ} \mathrm{C}\right)$

$\theta^{\mathrm{B}}$ temperature at embedded shear bands $\left({ }^{\circ} \mathrm{C}\right)$

$\theta^{\mathrm{M}}$ temperature at matrix $\left({ }^{\circ} \mathrm{C}\right)$

$\theta^{0} \quad$ reference temperature $\left({ }^{\circ} \mathrm{C}\right)$

$\mu_{\mathrm{L}} \quad$ liquid viscosity (Pa s)

$v$ Poisson coefficient

$\rho$ density of mixture $\left(\mathrm{kg} / \mathrm{m}^{3}\right)$

$(\rho c)_{\mathrm{m}} \quad$ specific heat of mixture $\left(\mathrm{J} /\left(\mathrm{m}^{3}{ }^{\circ} \mathrm{C}\right)\right)$

$\rho_{\mathrm{L}} \quad$ liquid density $\left(\mathrm{kg} / \mathrm{m}^{3}\right)$

$\rho_{\mathrm{L}}^{0} \quad$ liquid density at reference liquid pressure and temperature $\left(\mathrm{kg} / \mathrm{m}^{3}\right)$

$\rho_{\mathrm{S}} \quad$ solid density $\left(\mathrm{kg} / \mathrm{m}^{3}\right)$

$\rho_{\mathrm{S}}^{0} \quad$ solid density at reference temperature $\left(\mathrm{kg} / \mathrm{m}^{3}\right)$

$\sigma$ Cauchy total stress tensor $(\mathrm{Pa})$

$\sigma_{\mathrm{n}}$ total normal stress $(\mathrm{Pa})$

$\sigma^{\prime} \quad$ Cauchy effective stress tensor $(\mathrm{Pa})$

$\tau_{\mathrm{f}} \quad$ final shear strength $(\mathrm{Pa})$

$\phi^{\prime} \quad$ effective friction angle (degrees)

$\psi_{\mathrm{L}} \quad$ energy transfer coefficient $\left(\mathrm{kg} /\left(\mathrm{m}^{3} \mathrm{~s} \mathrm{~Pa}\right)\right)$

$\psi_{\theta} \quad$ liquid transfer coefficient $\left(\mathrm{J} /\left(\mathrm{m}^{3} \mathrm{~s}{ }^{\circ} \mathrm{C}\right)\right)$

$\boldsymbol{\nabla}(\cdot) \quad$ divergence vector operator $(1 / \mathrm{m})$

\section{REFERENCES}

Alonso, E. E. \& Pinyol, N. M. (2010). Criteria for rapid sliding I. A review of Vaiont case. Engng Geol. 114, No. 3-4, 198-210.

Alonso, E. E. \& Pinyol, N. M. (2012). The Vaiont landslide revisited. In Proceedings of the 2nd Italian workshop on landslide. Large slow active slope movements and risk management (eds L. Picarelli, R. Greco and G. Urciuoli), pp. 9-24. Salerno, Italy: Cooperativa Universitaria Editrice Studi.

Alonso, E. E., Zervos, A. \& Pinyol, N. M. (2016). Thermo-poromechanical analysis of landslides: from creeping behaviour to catastrophic failure. Géootechnique 66, No. 3, 202-219, http://dx.doi.org/10.1680/jgeot.15.LM.006.

Alshibli, K. A. \& Hasan, A. (2008). Spatial variation of void ratio and shear band thickness in sand using X-ray computed tomography. Géotechnique 58, No. 4, 249-257, http://dx.doi.org/ 10.1680/geot.2008.58.4.249.

Biot, M. A. (1941). General theory of three-dimensional consolidation. J. Appl. Phys. 12, No. 2, 155-164.

Biot, M. A. (1962). Mechanics of deformation and acoustic propagation in porous media. J. Appl. Phys. 33, No. 4, 1482-1498.

Cao, T. D., Sanavia, L. \& Schrefler, B. A. (2016). A thermo-hydromechanical model for multiphase geomaterials in dynamics with application to strain localization simulation. Int. J. Numer. Methods Engng 107, No. 4, 312-337.

Cecinato, F. \& Zervos, A. (2012). Influence of thermomechanics in the catastrophic collapse of planar landslides. Can. Geotech. J. 49, No. 2, 207-225.

Cecinato, F., Zervos, A. \& Veveakis, E. (2010). A themo-mechanical model for the catastrophic collapse of large landslides. Int. J. Numer. Analyt. Methods Geomech. 35, No. 14, $1507-1535$.

Ciabatta, M. (1964). La dinamica della frana del Vajont. Giornale di Geologia XXXII, No. I, 139-154 (in Italian).

Ferri, F., Di Toro, G., Hiroso, T. \& Shimamoto, T. (2010). Evidence of thermal pressurization in high-velocity friction experiments on smectite-rich gouges. Terra Nova 22, No. 5, 347-353.

Ferri, F., Di Toro, G., Hirose, T., Han, R., Noda, H., Shimamoto, T., Quaresimin, M. \& de Rossi, N. (2011). Low- to high-velocity frictional properties of the clay-rich gouges from the slipping 
zone of the 1963 Vaiont slide, northern Italy. J. Geophys. Res. 116, No. B9, B09208.

Gajo, A. \& Denzer, R. (2011). Finite element modelling of saturated porous media at finite strains under dynamic conditions with compressible constituents. Int. J. Numer. Methods Engng 85, No. 13, 1705-1736.

Goren, L. \& Aharonov, E. (2007). Long runout landslides: The role of frictional heating and hydraulic diffusivity. Geophys. Res. Lett. 34, No. 7, L07301.

Goren, L. \& Aharonov, E. (2009). On the stability of landslides: a thermo-poro-elastic approach. Earth Planet. Sci. Lett. 277, No. 3-4, 365-372.

Goren, L., Aharonov, E. \& Anders, M. H. (2010). The long runout of the Heart Mountain landslide: heating, pressurization, and carbonate decomposition. J. Geophys. Res.: Solid Earth 115, No. B10, B10210.

Habib, P. (1967). Sur un mode de glissement des massifs rocheux. Comptes Rendus Acad. Sci. Paris, Ser. A 264, 151-153 (in French).

He, S. M., Liu, W. \& Wang, J. (2015). Dynamic simulation of landslide based on thermo-poro-elastic approach. Comput. Geosci. 75, 24-32, https://doi.org/10.1016/j.cageo.2014.10.013.

Hendron, A. J. \& Patton, F. D. (1985). The Vaiont slide, a geotechnical analysis based on new geological observations of the failure surface, Technical Report GL-85-5. Washington, DC, USA: US Army Corps of Engineers.

Huang, M., Zhong, Q. Y., Tham, L. G. \& Zienkiewicz, O. C.(2004). On the stable finite element procedures for dynamic problems of saturated porous media. Int. J. Numer. Methods Engng 61, No. 9, 1421-1450.

Jeremic, B., Cheng, Z., Taiebat, M. \& Dafalias, Y. (2008). Numerical simulation of fully saturated porous materials. Int. J. Numer. Analyt. Methods Geomech. 32, No. 13, 1635-1660.

Lòpez-Querol, S., Fernández-Merodo, J. A., Mira, P. \& Pastor, M. (2007). Numerical modelling of dynamic consolidation on granular soils. Int. J. Numer. Analyt. Methods Geomech. 32, No. 12, 1431-1457.

Mühlhaus, H. B. \& Vardoulakis, I. (1987). The thickness of shear bands in granular materials. Géotechnique 37, No. 3, 271-283, http://dx.doi.org/10.1680/geot.1987.37.3.271.

Müller, L. (1964). The rock slide in the Vajont Valley. Rock Mech. Engng Geol. 2, No. 3-4, 148-212.

Nonveiller, E. (1987). The Vajont reservoir slope failure. Engng Geol. 24, No. 1-4, 493-512.

Paronuzzi, P. \& Bolla, A. (2015). Gravity-induced rock mass damage related to large en masse rockslides: evidence from Vajont. Geomorphology 234, 28-53, https://doi.org/10.1016/j.geomorph. 2015.01.008.

Pastor, M., Zienkiewicz, O. C. \& Chan, A. H. C. (1990). Generalized plasticity and the modelling of soil behaviour. Int. J. Numer. Analyt. Methods Geomech. 14, No. 3, 151-190.

Pinyol, N. M. \& Alonso, E. E. (2010a). Criteria for rapid sliding II. Thermo-hydro-mechanical and scale effects in Vaiont case. Engng Geol. 114, No. 3-4, 211-227.

Pinyol, N. M. \& Alonso, E. E. (2010b). Fast planar slides. A closed-form thermo-hydro-mechanical solution. Int. J. Numer. Analyt. Methods Geomech. 34, No. 1, 27-52.

Prevost, J. H. (1980). Mechanics of continuous porous media. Int. J. Engng Sci. 18, No. 6, 787-800.

Scarpelli, G. \& Wood, D. M. (1982). Experimental observations of shear band patterns in direct shear tests. In Proceedings of the IUTAM conference on deformation and failure of granular materials (eds P. A. Vermeer and H. J. Luger), pp. 473-484. Rotterdam, the Netherlands: Balkema.

Schrefler, B. A. \& Scotta, R. (2001). A fully coupled dynamic model for two-phase fluid flow in deformable porous media. Comput. Methods Appl. Mech. Engng 190, No. 24-25, 3223-3246.
Semenza, E. (2001). La storia de Vaiont raccontata del geologo che ha scoperto la frana. Ferrara, Italy: Editori Multimediale (in Italian).

Sulsky, D., Zhou, S. J. \& Schreyer, H. L. (1995). Application of a particle-in-cell method to solid mechanics. Comput. Phys. Communs 87, No. 1-2, 236-252.

Tika, T. E. \& Hutchinson, J. N. (1999). Ring shear tests on soil from the Vaiont landslide slip surface. Géotechnique 49, No. 1, 59-74, http://dx.doi.org/10.1680/geot.1999.49.1.59.

Uriel Romero, S. \& Molina, R. (1977). Kinematic aspects of Vaiont slide. In Proceedings of the 3rd international conference of the ISRM, pp. 865-870. Denver, CO, USA: National Academy of Sciences 2B.

Uzuoka, R. \& Borja, R. I. (2012). Dynamic of unsaturated poroelastic solids at finite strain. Int. J. Numer. Analyt. Methods Geomech. 36, No. 13, 1535-1573.

Vardoulakis, I. (1980). Shear band inclination and shear modulus of sand in biaxial tests. Int. J. Numer. Analyt. Methods Geomech. 4, No. 2, 113-119.

Vardoulakis, I. (2000). Catastrophic landslides due to frictional heating of the failure plane. Mech. Cohesive-frictional Mater. 5, No. 6, 443-467.

Vardoulakis, I. (2002). Dynamic thermo-poro-mechanical analysis of catastrophic landslides. Géotechnique 52, No. 3, 157-171, http://dx.doi.org/10.1680/geot.2002.52.3.157.

Verruijt, A. (2010). An introduction to soil dynamics. Vol. 24: theory and applications of transport in porous media. Berlin and Heidelberg, Germany: Springer Verlag.

Veveakis, E., Vardoulakis, I. \& Di Toro, G. (2007). Thermoporomechanics of creeping landslides: the 1963 Vaiont slide, northern Italy. J. Geophys. Res. 112, No. F3, F03026.

Voight, B. \& Faust, C. (1982). Frictional heat and strength loss in some rapid landslides. Géotechnique 32, No. 1, 43-54, http://dx.doi.org/10.1680/geot.1982.32.1.43.

Wolter, A., Stead, D. \& Clague, J. J. (2014). A morphologic characterisation of the 1963 Vajont Slide, Italy, using long-range terrestrial photogrammetry. Geomorphology 206, 147-164, https://doi.org/10.1016/j.geomorph.2013.10.006.

Yerro, A., Alonso, E. E. \& Pinyol, N. M. (2016a). Run-out of landslides in brittle soils. Comput. Geotech. 80, 427-439, https://doi.org/10.1016/j.compgeo.2016.03.001.

Yerro, A., Pinyol, N. M. \& Alonso, E. E. (2016b). Internal progressive failure in deep-seated landslides. Rock Mech. Rock Engng 49, No. 6, 1-16.

Zabala, F. \& Alonso, E. E. (2011). Progressive failure of Aznalcóllar dam using the material point method. Géotechnique 61, No. 9, 795-808, http://dx.doi.org/10.1680/geot.9.P.134.

Zabala, F., Rodari, R. \& Oldecop, L. (2004). Localización de deformaciones en estructuras utilizando el Método del Punto Material. Revista Engenharia Estrutural 1290, No. 5400, 11-29 (in Spanish).

Zhang, H. W., Wang, K. P. \& Chen, Z. (2009). Material point method for dynamic analysis of saturated porous media under external contact/impact of solid bodies. Comput. Methods Appl. Mech. Engng 198, No. 17-20, 1456-1472.

Zienkiewicz, O. C. \& Shiomi, T. (1984). Dynamic behaviour of saturated porous media: the generalized Biot formulation and its numerical solution. Int. J. Numer. Analyt. Methods Geomech. 8, No. $1,71-96$.

Zienkiewicz, O. C., Chang, C. T. \& Bettess, P. (1980). Drained, undrained, consolidating and dynamic behaviour assumptions in soils. Géotechnique 30, No. 4, 385-395, http://dx.doi.org/ 10.1680/geot.1980.30.4.385

Zienkiewicz, O. C., Chan, A. H. C., Pastor, M., Schrefler, B. A. \& Shiomi, T. (1999). Computational geomechanics with special reference to earthquake engineering. Chichester, UK: Wiley. 